\title{
Cyperaceae do rio Apodi-Mossoró, Estado do Rio Grande do Norte, Brasil
}

\author{
André Rodolfo de Oliveira Ribeiro ${ }^{1,6}$, Ana Paula do Nascimento Prata ${ }^{2}$, Ramiro Gustavo Valera Camacho, \\ Odaci Fernandes de Oliveira ${ }^{4}$ Regina Célia de Oliveira ${ }^{5}$
}

Recebido: 8.04.2013; aceito: 3.12 .2013

ABSTRACT - (Cyperaceae in the Apodi-Mossoró River, Rio Grande do Norte State, Brazil). The Apodi-Mossoró River, located in the Caatinga biome, has its course characterized by diverse landscape sand humid environments, as well as by many members of the family Cyperaceae. Studies on the flora of Cyperaceae are scarce in northeastern Brazil and nonexistent for Rio Grande do Norte State. Twenty-one botanical expeditions were undertaken in this area during the period from July 2007 to May 2008 on four main points in the municipalities of Felipe Guerra, Governador Dix-Sept Rosado, Luís Gomes, and Mossoró. Seven genera and twenty-five species of Cyperaceae were found in the Apodi-Mossoró River, twenty-one of which are new records for Rio Grande do Norte State.This figure more than doubled the number of species of the family known to occur in this Brazilian State. Botanical descriptions, taxonomic comments, identification keys, and illustrations are provided.

Keywords: macrophytes, monocots, riparian vegetation, sedges

RESUMO - (Cyperaceae do rio Apodi-Mossoró, Estado do Rio Grande do Norte, Brasil). O rio Apodi-Mossoró, inserido no Bioma Caatinga, tem seu curso caracterizado por diversidade de ambientes úmidos e representantes da família Cyperaceae. Estudos sobre a flora de Cyperaceae são escassos na região Nordeste do Brasil e inexistentes para o Estado do Rio Grande do Norte. Foram realizadas 21 coletas mensais no período de julho de 2007 a maio de 2008, em quatro pontos principais, nos municípios de Felipe Guerra, Governador Dix-Sept Rosado, Luís Gomes e Mossoró. Registrou-se a ocorrência de 25 espécies distribuídas em sete gêneros de Cyperaceae no rio Apodi-Mossoró, 21 das quais são novas ocorrências para o Estado do Rio Grande do Norte, mais que duplicando o número de espécies de Cyperaceae conhecidas para o Estado. São fornecidas descrições botânicas, comentários taxonômicos, chaves de identificação e ilustrações.

Palavras-chave: ciperáceas, macrófitas, monocotiledôneas, vegetação ripária

\section{Introdução}

O rio Apodi-Mossoró tem seu curso restrito ao Estado do Rio Grande do Norte, percorrendo áreas de caatinga da nascente até a foz. As áreas de vegetação ciliar dos principais rios dos Estados do Piauí, Ceará e Rio Grande do Norte foram descritas por Andrade-Lima (1981) como uma fitofisionomia com predomínio de Licania-Geoffroea-Copernicia. Embora esta associação de espécies predomine ao longo do curso do rio Apodi-Mossoró, o que se vê, dos poucos e raros fragmentos de vegetação nativa, é um mosaico vegetacional complexo e variável ao longo do gradiente leito-tabuleiro entre nascente e foz.

Nascimento et al. (2003) e Souza \& Rodal (2010) demonstraram, quantitativamente, as diferenças da

1. Universidade de Brasília, Instituto de Ciências Biológicas, Departamento de Botânica, Caixa Postal 04457, 70.919-970 Brasília, DF, Brasil

2. Universidade Federal do Sergipe, Centro de Ciências Biológicas e da Saúde, Campus Universitário Professor Aloísio de Campos, 49100-000 Aracaju, SE, Brasil

3. Universidade do Estado do Rio Grande do Norte, Departamento de Ciências Biológicas, Caixa-Postal 70, 59633-010 Mossoró, RN, Brasil

4. Universidade Federal Rural do Semi-Árido, Departamento de Ciências Vegetais, Setor de Fitossanidade, Av. Francisco Mota, 572, Bairro Costa e Silva, 59.625-900 Mossoró, RN, Brasil

5. Universidade de Brasília, Instituto de Ciências Biológicas, Departamento de Botânica, Caixa Postal 04457, 70.919-970 Brasília, DF, Brasil

6. Autor para correspondência: andre_rodolf@hotmail.com 
vegetação ciliar em termos de gradiente leito-tabuleiro para um trecho do rio São Francisco e do rio Pajeú, ambos no Estado de Pernambuco. Nascimento et al. (2003) relataram a presença de diques marginais no rio São Francisco paralelos às matas ciliares formando lagoas temporárias, com flora semelhante à da mata ciliar, distinta das áreas do pediplano sertanejo ou tabuleiro. Estes autores comentaram que a semelhança florística deve-se ao fato de as flutuações do nível do rio influenciarem nas características pedológicas destes ambientes (mata ciliar e dique $\times$ tabuleiro). Diques marginais resultantes da inundação também podem ser observados ao longo do rio Apodi-Mossoró.

As áreas de vegetação ciliar são importantes centros de diversidade e abrigam muitas espécies raras e endêmicas (Silva et al. 2004). Os resultados dos raros estudos florísticos no âmbito de vegetação ciliar, no que diz respeito aos rios inseridos no bioma Caatinga, quando considerada em sua totalidade e não apenas as espécies arbóreas, mostram que as herbáceas predominam neste tipo de vegetação (Araújo et al. 2005, Souza \& Rodal 2010). Segundo relato de HenrySilva et al. (2010), as famílias Poaceae e Cyperaceae contribuem com $30 \%$ das espécies de macrófitas existentes na área de ocupação do rio Apodi-Mossoró.

A família Cyperaceae é cosmopolita e está representada por cerca de 5.000 espécies distribuídas em 104 gêneros (Goetghebeur 1998). No Brasil, foram catalogadas 621 espécies distribuídas em 40 gêneros, 177 das quais são endêmicas do país (Alves et al. 2012).

No Nordeste do Brasil, os estudos com Cyperaceae são escassos, raramente fornecendo descrições botânicas representando o padrão morfológico das espécies em nível regional. Na região Nordeste, os únicos trabalhos realizados foram os de Luceño et al. (1997) que catalogaram as espécies de Cyperaceae dos Estados da Paraíba e Pernambuco; Souza \& Conceição (2009) que listaram as espécies de Cyperaceae ocorrentes no município de Caxias(MA); Freitas et al. (2011) que compôs um checklist das monocotiledôneas do Estado do Ceará; e Alves \& Martins (2009) sobre as Cyperaceae da Flora de Mirandiba(PE), sendo este o único no qual foram apresentadas descrições botânicas. Para o rio Apodi-Mossoró, Henry-Silva et al. (2010) avaliaram a riqueza e distribuição das macrófitas aquáticas, listando sete espécies de Cyperaceae, porém sem incluir chaves de identificação e descrições morfológicas.
O fato de, na lista de espécies da Flora do Brasil, Alves et al. (2012) documentarem a ocorrência de apenas 17 espécies de Cyperaceae distribuídas em oito gêneros no Estado do Rio Grande do Norte, número bem menor que o encontrado no presente estudo, reforça ainda mais a necessidade de melhorar a representatividade, em coleções de herbário, dos táxons de Cyperaceae provenientes deste Estado.

Os objetivos deste trabalho são ampliar a representatividade dos táxons de Cyperaceae com o levantamento sistemático ao longo do rio ApodiMossoró; descrever e fornecer subsídios para a identificação de tais táxons.

\section{Material e métodos}

O rio Apodi-Mossoró localiza-se no Nordeste do Brasil, sendo restrito ao Estado do Rio Grande do Norte. Nasce no município de Luís Gomes (6²4'50"S, $\left.38^{\circ} 23^{\prime} 20^{\prime \prime} \mathrm{W}\right)$ e desemboca no Oceano Atlântico ( $\left.4^{\circ} 56^{\prime} 14^{\prime \prime} \mathrm{S}, 37^{\circ} 09^{\prime} 23^{\prime \prime} \mathrm{W}\right)$, entre os municípios de Areia Branca e Grossos (figura 1). Destacam-se dois ambientes ao longo da vegetação ciliar ao ApodiMossoró, o primeiro, observado nos municípios de Governador Dix-Sept Rosado e Mossoró, caracterizado pelo relevo plano e presença de diques adjacentes ao rio; e o segundo, no município de Luís Gomes e nas imediações da nascente, caracterizado pelo relevo fortemente ondulado, maior altitude, clima mais úmido, grande número de riachos periódicos, mata ciliar circundada por floresta caducifólia, incluindo Caatinga Hipoxerófila e Floresta Subcaducifólia (IDEMA 2007).

Foram realizadas 21 coletas botânicas mensais no período de julho de 2007 a agosto de 2008, em quatro pontos principais, selecionados por apresentarem maior cobertura vegetal, nos municípios de Felipe Guerra, Governador Dix-Sept Rosado, Luís Gomes e Mossoró (figura 1). Realizaram-se, ainda, coletas adicionais nos municípios de Apodi, Areia Branca, Francisco Dantas e Riacho de Santana. Os vouchers foram incorporados ao herbário MOSS, da Universidade Federal Rural do Semiárido, Mossoró-RN e as duplicatas distribuídas aos herbários ASE, EAC, MAC, UB, UFP e UFRN (acrônimos disponíveis em Thiers 2013).

As técnicas de coleta foram as usuais em taxonomia e descritas em Walter \& Cavalcanti (2005). As identificações foram realizadas com base na literatura especializada. As descrições dos caracteres basearam-se em Radford et al. (1974). 


\section{Resultados e Discussão}

Na vegetação ciliar do rio Apodi-Mossoró, foram encontradas 25 espécies de Cyperaceae, distribuídas em sete gêneros, todas já citadas para o Brasil e Região Nordeste por Alves et al. (2009). Dentre estas, com base na lista mais recente de Alves et al. (2012), apenas quatro haviam sido citadas para o Estado do Rio Grande do Norte, Cyperus ligularis L., C. surinamensis Rottb., Pycreus macrostachyos (Lam.) J. Raynal e P. polystachyos (Rottb.) P. Beauv. O presente trabalho contribui, portanto, com 21 novas ocorrências, mais que duplicando o número de espécies de Cyperaceae conhecidas para o Estado.

Também são relevantes as primeiras citações dos gêneros Eleocharis R. Br., Fimbristylis Vahl, Lipocarpha R. Br. e Scleria P.J. Bergius para o Estado do Rio Grande do Norte. A quantidade de novas ocorrências é primordialmente explicada pela inexistência de estudos específicos sobre Cyperaceae no Estado, evidenciando que os estudos de flora regionais são indispensáveis para um conhecimento mais detalhado da biodiversidade brasileira.

Foram observadas diferenças no padrão de distribuição das espécies. Algumas apresentaram

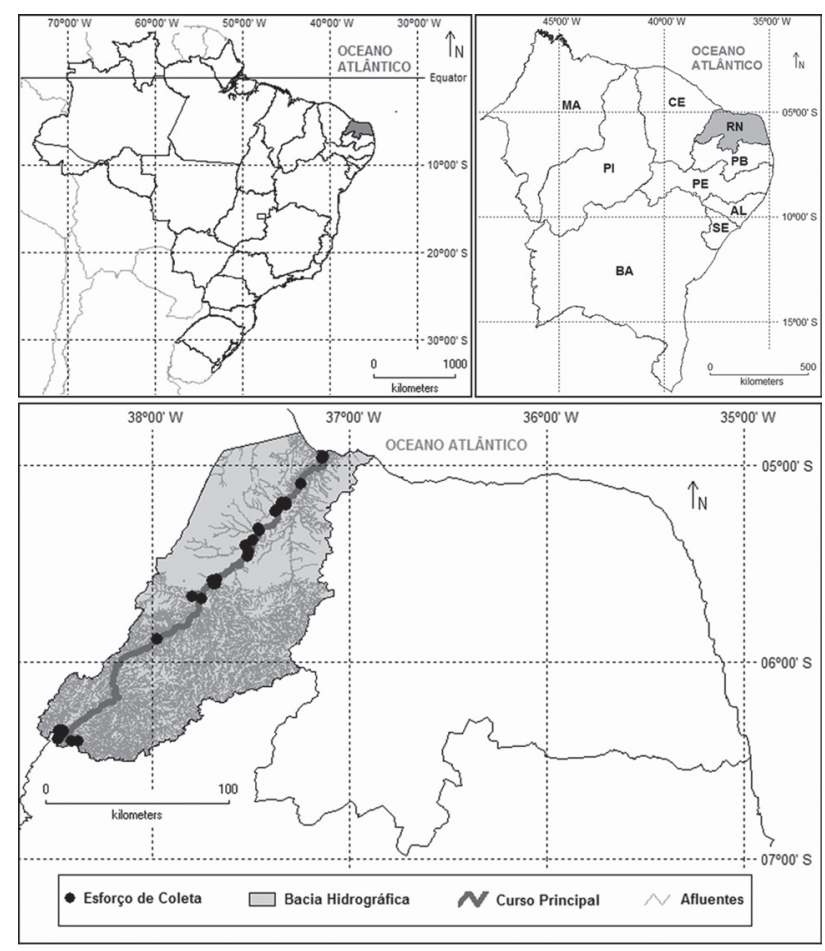

Figura 1. Localização da bacia do rio Apodi-Mossoró, Rio Grande do Norte, e pontos de amostragem de Cyperaceae.

Figure 1. Visited points in the Apodi-Mossoró River Basin, Rio Grande do Norte State, Brazil. distribuição ampla: Cyperus compressus L., C. squarrosus L., Eleocharis geniculata (L.) Roem. \& Schult. e Lipocarpha micrantha (Vahl) G.C. Tucker, ocorrendo desde a nascente do rio até o município de Mossoró. Luceño et al. (1997), em sucintos comentários, citou a relação de $C$. compressus e E. geniculata com ambientes alterados ou solos pobres nos Estados da Paraíba e Pernambuco. No entanto, C. squarrosus e L. micrantha mostraram ocorrência em maior diversidade de habitats do que o indicado por Luceño et al. (1997), vegetando não somente em ambientes arenosos ou úmidos, mas também em ambientes rupícolas, encharcados ou mesmo alterados pela interferência antrópica na nascente, ou ainda em solos argilosos do município de Mossoró.

Outras espécies foram observadas, até o momento, somente em um município. O município de Luís Gomes, no qual se localiza a nascente do rio, apresentou a maior quantidade de espécies exclusivas, Cyperus aggregatus (Willd.) Endl., C. cuspidatus Kunth, C. distans L. f., C. laxus Lam. e Scleria reticularis Michx. Os municípios de Francisco Dantas, Felipe Guerra e Mossoró apresentaram uma espécie exclusiva, Eleocharis minima Kunth, Fimbristylis dichotoma (L.) Vahl e Eleocharis mutata (L.) Roem. \& Schult., respectivamente.

A maior diversidade de Cyperaceae foi encontrada nos lagos formados pelos diques marginais no município de Mossoró, com 17 espécies. Neste ambiente prevalecem populações com predomínio de Eleocharis mutata (L.) Roem. \& Schult., que por vezes chegam a encobrir todo o espelho d'água do lago, como aquática emergente. Destacam-se também, populações de Cyperus articulatus L., na margem ou também como aquática emergente, Eleocharis geniculata e Fimbristylis cymosa R. Br. Estas quatro espécies permanecem durante todo o ano, mesmo na época mais seca, e parecem ser tolerantes aos ambientes salinos das planícies fluviomarinhas do rio Apodi-Mossoró. Gil \& Bove (2007) também verificaram a ocorrência de E. mutata em lagos ou diques adjacentes a rios no Estado do Rio de Janeiro, formando comunidades com E. geniculata, salientando a presença destas duas espécies em locais de grande salinidade.

Conforme a ocorrência por município tem-se Luís Gomes (16 spp.), Governador Dix-Sept Rosado (sete spp.) e Felipe Guerra (seis spp.). Em Luís Gomes, na época seca, alguns leitos arenosos dos inúmeros riachos periódicos ainda preservam água nas camadas subsuperficiais. Nestes leitos, são frequentes Cyperus laxus Lam., Eleocharis geniculata, Pycreus macrostachyos (Lam.) J. Raynal e Rhynchospora 
contracta (Nees) J. Raynal. Luceño et al. (1997) comentaram a preferência de $C$. laxus por ambientes sombreados nos Estados da Paraíba e Pernambuco. Comportamento similar foi observado para $C$. laxus na nascente do rio Apodi-Mossoró, a qual é restrita ao interior ou borda da Floresta Caducifólia. $\mathrm{Na}$ estação chuvosa, ocorre considerável aumento no número de espécies e surgem populações de Cyperus compressus, C. cuspidatus Kunth, C. squarrosus L., Lipocarpha micrantha (Vahl) G.C. Tucker e Pycreus fugax (Liebm.) C.D. Adams. Vale salientar o hábito de $C$. cuspidatus muito reduzido, com touceiras não ultrapassando $6,5 \mathrm{~cm}$ de altura e as inflorescências representando quase a totalidade do tamanho da planta.

No município de Governador Dix Sept Rosado, são visíveis as inflorescências congestas de coloração amarela a dourada de Pycreus polystachyos (Rottb.) P. Beauv., que compõe a paisagem da margem do rio ou como aquática emergente; em Felipe Guerra, entre os terrenos pedregosos da cachoeira do Roncador, estão entre os principais componentes Eleocharis geniculata, Fimbristylis dichotoma e Lipocarpha micrantha.

Cyperaceae Juss., Gen. P1.: 26 (1789).

Ervas cespitosas ou rizomatosas. Escapos trígonos ou cilíndricos. Folhas sésseis, alternas espiraladas, formando rosetas basais ou espaçadas em entrenós desenvolvidos; lâmina foliar presente ou ausente; bainhas fechadas. Inflorescências simples ou compostas, uniespiculadas ou pluriespiculadas, antelas, racemos, corimbos, glomérulos, espigas, grupos digitados ou fascículos seriados. Espiguetas uni ou bissexuadas, 2-plurifloras. Glumas férteis ou estéreis. Flores uni ou bissexuadas envolvidas por uma gluma; perianto presente ou ausente, modificado em cerdas (6-7) ou em hipogínio trilobado. Ovário uniovulado, placentação basal, ereta. Estames 1-3, livres; anteras rimosas, ditecas. Estilete linear, subulado ou deltoide, base persistente ou decídua; estigmas 2-3, glabros ou fimbriados. Fruto aquênio.

Chave para identificação dos gêneros de Cyperaceae do rio Apodi-Mossoró

1. Glumas disticamente dispostas 2

2. Contralígula presente; flores unissexuadas; hipogínio presente Scleria

2. Contralígula ausente; flores bissexuadas; hipogínio ausente 3

3. Estigmas 2; aquênio lenticular Pycreus

3. Estigmas 3; aquênio trígono a subcilíndrico Cyperus

1. Glumas (ou brácteas da espigueta glumiformes em Lipocarpha) espiraladamente dispostas Eleocharis

4. Lâmina foliar e brácteas de $1^{\mathrm{a}}$ ordem ausentes; inflorescência uniespiculada 4

4. Lâmina foliar e brácteas de $1^{\mathrm{a}}$ ordem presentes; inflorescência 3-pluriespiculada ..... 5

5.Estilopódio presente; superfície do aquênio transversalmente rugosa Rhynchospora

5.Estilopódio ausente; superfície do aquênio papilosa, reticulada com rugas longitudinais ou irregular com algumas verrugas 6

6. Inflorescência em antela simples ou composta; glumas presentes e bem desenvolvidas, brácteas da espigueta distintas das glumas; estigmas fimbriados; superfície do aquênio reticulada com rugas longitudinais ou irregular, às vezes com verrugas Fimbristylis

6. Inflorescência em espiga ovoide, simples, séssil, semelhante a uma espigueta, ou composta por glomérulo de 2-5 espigas ovoides sésseis; glumas reduzidas ou ausentes, brácteas da espigueta glumiformes; estigmas glabros; superfície do aquênio papilosa, às vezes reticulada sem rugas longitudinais

Lipocarpha

1. Cyperus L., Sp. Pl.: 44 (1753).

Lâmina foliar ausente ou presente. Contralígula ausente. Brácteas de $1^{\mathrm{a}}$ ordem presentes. Inflorescência terminal, simples ou composta, antelas, glomérulos, espigas, grupos digitados ou fascículos seriados. Espiguetas 3-várias por inflorescência, normalmente desenvolvidas, aparentes. Glumas presentes, 2-várias, disticamente arranjadas. Flores bissexuadas, aperiantadas. Estilete decíduo; estigmas 3, glabros. Aquênio trígono, superfície papilosa, lisa ou reticulada com uma papila em cada célula. Estilopódio ausente. Cerdas periânticas ausentes. Hipogínio ausente. 
Chave para identificação das espécies de Cyperus do rio Apodi-Mossoró

1. Escapo cilíndrico, septos transversais presentes; lâminas foliares ausentes C. articulatus

1. Escapo trígono, septos transversais ausentes; lâminas foliares presentes

2. Escapo retrorsamente escabro C. surinamensis

2. Escapo glabro

3. Lâminas foliares cartáceas, glaucas

3. Lâminas foliares herbáceas, verdes

C. ligularis

4. Espigueta articulada em todos os nós da ráquila, formando diásporos constituídos de um segmento da ráquila, um aquênio e uma gluma; alas da ráquila esponjosas e quebradiças, tornando-se membranáceas nas margens .....

C. odoratus

4. Espigueta não articulada ou articulada apenas na base, formando diásporos constituídos por uma espigueta completa; alas da ráquila inteiramente membranáceas ou ausentes

5. Espigueta decídua, articulada na base

6. Alas da ráquila 0,6-1,2 $\mathrm{mm}$ compr.; gluma 1,6-2,4 mm larg., mútica ou mucronada, múcron até $0,2 \mathrm{~mm}$ compr.

C. aggregatus

6. Alas da ráquila ausentes ou até $0,1 \mathrm{~mm}$ compr.; gluma 0,6-0,8 $\mathrm{mm}$ larg., aristada, arista 0,5-1,6 mm compr.

C. squarrosus

5. Espigueta persistente, não articulada

7. Gluma persistente; antera 1,1-1,8 mm compr.

8. Gluma parda a ocrácea nas margens C. esculentus

8. Gluma vinácea, raramente pardo-vinácea nas margens C. rotundus

7. Gluma decídua, antera $0,1-0,9 \mathrm{~mm}$ compr.

9. Gluma mútica ou com múcron reduzido, medindo até $0,2 \mathrm{~mm}$ compr.

10. Entrenós da ráquila $0,2-0,3 \mathrm{~mm}$ compr.; glumas medianamente bicarenadas

11. Ráquis 1,2-2,9 mm compr.; espiguetas em glomérulo esférico ou hemisférico ou espiga globosa; aquênio 0,9-1 mm compr.

C. entrerianus

11. Ráquis 0,3-0,5 mm compr.; espiguetas em fascículo seriado; aquênio 0,6-0,8 $\mathrm{mm}$ compr.

C. surinamensis

10. Entrenós da ráquila 0,5-1,1 mm compr.; glumas medianamente unicarenadas

12. Entrenós da ráquila 0,8-1,1 mm compr.; gluma 1,9-2,2 $\times 0,9-1,1 \mathrm{~mm}$, castanho-vinácea a parda nas margens; estames 3; aquênio 1,4-1,5 mm compr.

C. distans

12. Entrenós da ráquila $0,5-0,7 \mathrm{~mm}$ compr.; gluma 1,2-1,6 $\times 1,4-1,8 \mathrm{~mm}$, amarela a pardo-amarelada nas margens; estames 2; aquênio 1,1-1,2 mm compr. C. iria

9. Gluma mucronada ou aristada com múcron/arista 0,3-1,2 mm compr.

13. Gluma 0,7-1 mm larg., 2-nervada, arista recurvada $60-90^{\circ}$; antera $0,1-0,2 \mathrm{~mm}$ compr.; aquênio $0,5-0,6 \times 0,3 \times 0,3 \mathrm{~mm}$ C. cuspidatus

13. Gluma 1,6-2,1 mm larg.; 8-16-nervada, arista reta ou levemente recurvada até $45^{\circ}$; antera 0,4-0,7 mm compr.; aquênio 1,1-1,5 × 0,8-1 × 0,7-0,9 $\mathrm{mm}$ compr.

14. Gluma 2,3-2,8 mm compr.; prolongamento do conectivo no ápice da antera ausente ou glabro; estilete 0,9-1,4 mm compr.; aquênio 1,1-1,2 mm compr .... C. compressus 14. Gluma 1,2-1,4 mm compr.; prolongamento do conectivo no ápice da antera antrorsamente escabro; estilete 0,1-0,2 mm compr.; aquênio 1,3-1,5 mm compr. ...... C. laxus

1.1. Cyperus aggregatus (Willd.) Endl., Cat. Horti Vindob. 1: 93 (1842).

Figura 2 a

Erva cespitosa ca. $45 \mathrm{~cm}$ alt. Escapo trígono, glabro, septos transversais ausentes. Lâmina foliar presente, $10-29 \mathrm{~cm} \times 4-6 \mathrm{~mm}$, herbácea, verde.
Inflorescência 2,3 × 3,5 cm, glomérulo hemisférico de espigas. Ráquis 5-18 mm compr., aparente ou não. Espigueta 2,2-4,3 × 1-1,4 × 0,6-1 mm. Ráquila articulada na base, espigueta caindo como uma unidade, entrenós 1,1-1,5 mm compr. Alas da ráquila presentes, 0,6-1,2 $\mathrm{mm}$ compr., membranáceas, 

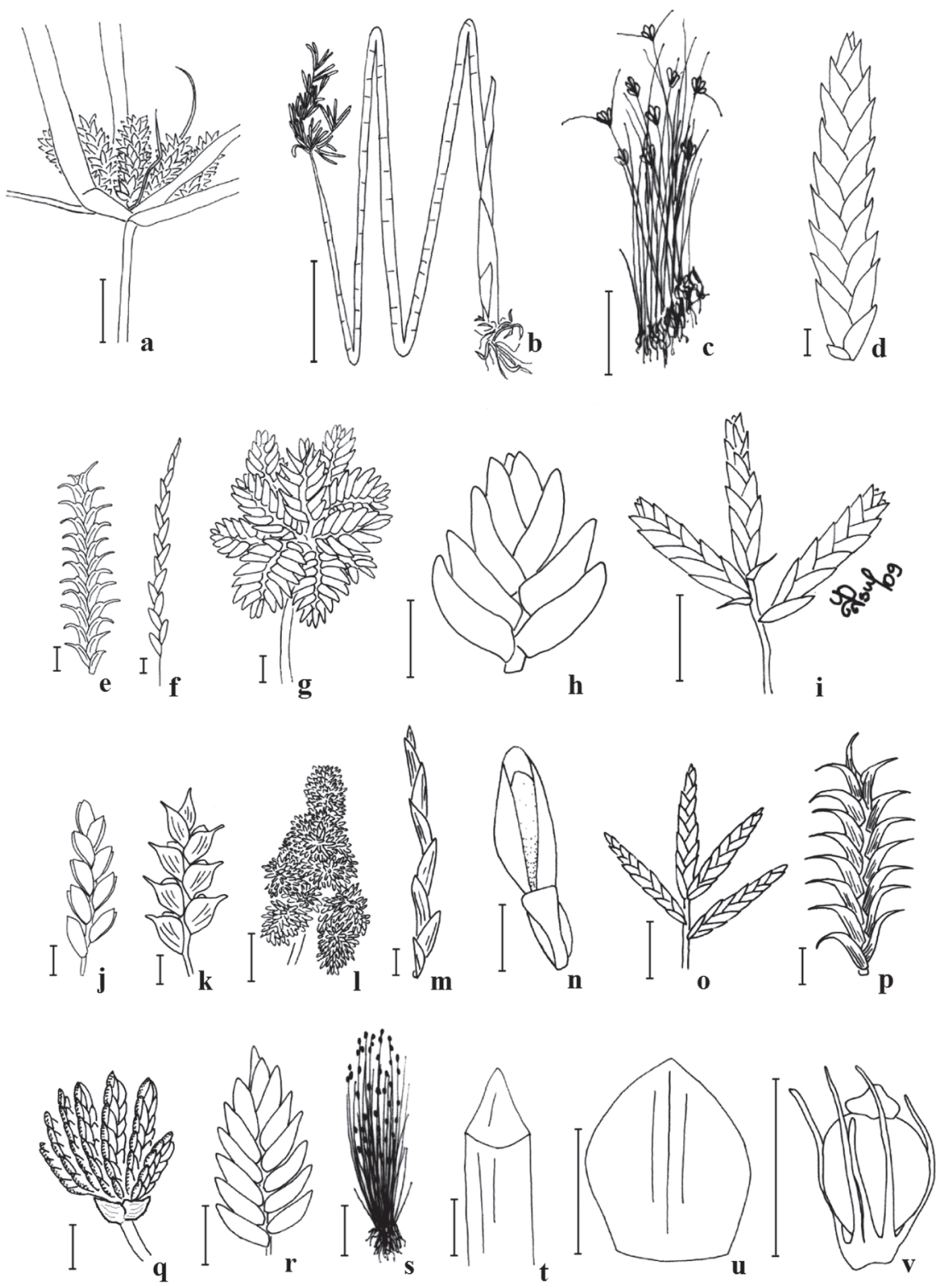

Figura 2. a. Cyperus aggregatus, inflorescência. b. C. articulatus, hábito mostrando escapo com septos transversais. c-d. C. compressus. c. Hábito. d. Espigueta. e. C. cuspidatus, espigueta. f. C. distans, espigueta. g-h. C. entrerianus. g. Glomérulo. h. Espigueta. i. C. esculentus, espiga. j. C. iria, espigueta. k. C. laxus, espigueta. 1. C. ligularis, inflorescência. m-n. C. odoratus. m. Espigueta. n. Diásporo (gluma envolvendo aquênio acima, segmento da ráquila abaixo). o. C. rotundus, espiga. p. C. squarrosus, espigueta. q-r. C. surinamensis. q. Fascículo seriado. r. Espigueta. s-v. Eleocharis geniculata. s. Hábito. t. Ápice da bainha. u. Gluma. v. Aquênio. Escalas: a. 1 cm. b-c. 10 cm. d-h. 1 mm. I. 1 cm. j-k. 1 mm. 1.1 cm. m-n. 1 mm. o. 1 cm. p-r. 1 mm. s. 5 cm. t-v. 1 mm. (a. A.R.O. Ribeiro et al. 175 . b. A.R.O. Ribeiro 155. c-d. A.R.O. Ribeiro 164. e. A.R.O. Ribeiro et al. 199. f. A.R.O. Ribeiro et al. 177. g-h. A.R.O. Ribeiro et al. 178. i. A.R.O. Ribeiro 170. j. A.R.O. Ribeiro et al. 172. k. A.R.O. Ribeiro et al. 206. 1. A.R.O. Ribeiro 19. m-n. A.R.O. Ribeiro 158. o. A.R.O. Ribeiro 161. p. A.R.O. Ribeiro 168. q-r. A.R.O. Ribeiro 157. s-v. A.R.O. Ribeiro 163).

Figure 2 a. Cyperus aggregatus, inflorescence. b. C. articulatus, habit. c-d. C. compressus. c. Habit. d. Spikelet. e. C. cuspidatus, spikelet. f. C. distans, spikelet. g-h. C. entrerianus. g. Glomerulus. h. Spikelet. i. C. esculentus, spike. j. C. iria, spikelet. k. C. laxus, spikelet. 1. C. ligularis, inflorescence. m-n. C. odoratus. m. Spikelet. n. Diaspore (glume involving achene above, rachilla segment below). o. C. rotundus, spike. p. C. squarrosus, spikelet. q-r. C. surinamensis. q. Serial fascicle. r. Spikelet. s-v. Eleocharis geniculata (L.) Roem. \& Schult. s. Habit. t. Sheath apex. u. Glume. v. Achene. Bars: a. $1 \mathrm{~cm}$. b-c. $10 \mathrm{~cm}$. d-h. $1 \mathrm{~mm} .1 .1 \mathrm{~cm}$. j-k. $1 \mathrm{~mm} .1 .1 \mathrm{~cm} . \mathrm{m}-\mathrm{n} .1 \mathrm{~mm}$. o. 1 cm. p-r. 1 mm. s. 5 cm. t-v. 1 mm. (a. A.R.O. Ribeiro et al. 175. b. A.R.O. Ribeiro 155. c-d. A.R.O. Ribeiro 164. e. A.R.O. Ribeiro et al. 199. f. A.R.O. Ribeiro et al. 177. g-h. A.R.O. Ribeiro et al. 178. i. A.R.O. Ribeiro 170. j. A.R.O. Ribeiro et al. 172. k. A.R.O. Ribeiro et al. 206. 1. A.R.O. Ribeiro 19. m-n. A.R.O. Ribeiro 158. o. A.R.O. Ribeiro 161. p. A.R.O. Ribeiro 168. q-r. A.R.O. Ribeiro 157. s-v. A.R.O. Ribeiro 163). 
hialinas ou hialino-esverdeadas, às vezes com manchas vináceas. Glumas 2-3, 2,1-3 × 1,6-2,4 mm, múticas, raramente mucronadas, medianamente 8-12-nervadas, unicarenadas, persistentes, pardas, pardo-esverdeadas ou pardo-amareladas, às vezes com manchas vináceas nas margens, verdes na carena; múcron até $0,2 \mathrm{~mm}$ compr., reto. Estames 3; antera $0,4-0,7 \times 0,1-0,2 \mathrm{~mm}$; prolongamento do conectivo ausente ou presente, até $0,1 \mathrm{~mm}$ compr., glabro. Estilete 0,3-1,1 mm compr. Aquênio 1,5-1,9 × 0,6-0,9 mm, com múcron ca. $0,1 \mathrm{~mm}$ compr., castanho.

Material examinado: BRASIL. Rio GRAnde do Norte: Luís Gomes, estrada para Tigre de Cima, margem de afluente do rio Apodi-Mossoró, próximo à ponte da Baixa do Almeida, 6 $6^{\circ} 23^{\prime} 53^{\prime \prime} \mathrm{S}, 38^{\circ} 24^{\prime} 36^{\prime \prime} \mathrm{W}$, 30-V-2008, fl. e fr., A.R.O. Ribeiro et al. 175 (ASE, EAC, MAC, MOSS, UB, UFP, UFRN).

Habita margens dos riachos que compõem a nascente do rio Apodi-Mossoró. Nos demais municípios do médio e baixo curso não foi encontrada na vegetação ribeirinha, apesar do seu registro além dos limites fluviais. Floração e frutificação na estação chuvosa, maio.

É reconhecida pela inflorescência em glomérulo, esférico ou hemisférico, de espigas de espiguetas; espigas densifloras, ráquis oculta; espiguetas esverdeadas ou amareladas com 2-3 glumas. As alas da ráquila são largas e envolvem o aquênio maduro.

\subsection{Cyperus articulatus L., Sp. P1.: 44 (1753). Figura $2 \mathrm{~b}$}

Erva rizomatosa $68-169 \mathrm{~cm}$. Escapo cilíndrico, glabro, septos transversais presentes. Lâmina foliar ausente. Inflorescência 2,7-13,8 × 2,2-8,8 cm; antela de espigas. Ráquis 2-2,9 mm compr., aparente. Espigueta (6)9-36 × 1,1-1,3 × 0,4-0,6 mm. Ráquila não articulada, espigueta persistente, entrenós $0,7-1,1 \mathrm{~mm}$ compr. Alas da ráquila presentes, $0,2-0,5 \mathrm{~mm}$ compr., membranáceas, hialinas, às vezes com manchas vináceas. Glumas (8)12-29, 2,6-3,5 × 1,1-1,6 mm, múticas, raramente mucronadas, medianamente 4-10-nervadas; unicarenadas, decíduas, pardas, pardoamareladas ou pardo-vináceas nas margens, verdes na carena; múcron até $0,1 \mathrm{~mm}$ compr., reto. Estames 3; antera 1,3-1,9 × 0,1-0,3 $\mathrm{mm}$; prolongamento do conectivo ausente ou presente no ápice da antera, até $0,1 \mathrm{~mm}$ compr., glabro. Estilete 0,5-1,1 mm compr. Aquênio 1,1-1,3 × 0,5-0,7 mm, com múcron ca. $0,1 \mathrm{~mm}$ compr., castanho.

Material examinado: BRASIL. Rio GRANDE DO NoRTE: Mossoró, a $2 \mathrm{~km}$ da torre da olaria, 509'43"S,
37017'21"W, 10-VIII-2007, fl. e fr., A.S. Silva et al. 3 (ASE, EAC, MAC, MOSS, UB, UFP, UFRN); margem de lago próximo à Feira do Bode, próximo ao Rio Apodi-Mossoró, 5¹1'58"S, 37²19'31"W, 19-X-2007, fl., A.R.O. Ribeiro 17 (ASE, EAC, MAC, MOSS, UB, UFP, UFRN); 29-I-2008, fl. e fr., A.R.O. Ribeiro 103 (ASE, EAC, MAC, MOSS, UB, UFP, UFRN); 28-II-2008, fl., A.R.O. Ribeiro 116 (ASE, EAC, MAC, MOSS, UB, UFP, UFRN); 28-III-2008, fl., A.R.O. Ribeiro 125 (ASE, EAC, MAC, MOSS, UB, UFP, UFRN); 24-IV-2008, fl., A.R.O. Ribeiro \& A.M.S. Araújo 136 (ASE, EAC, MAC, MOSS, UB, UFP, UFRN); 21-V-2008, fl. e fr., A.R.O. Ribeiro 155 (ASE, EAC, MAC, MOSS, UB, UFP, UFRN); margem do Rio Apodi-Mossoró, atrás do Cartódromo, $5^{\circ} 11^{\prime} 56^{\prime \prime} \mathrm{S}, 37^{\circ} 19^{\prime} 42^{\prime \prime} \mathrm{W}, 31-\mathrm{XII}-2007$, fl., A.R.O. Ribeiro 91 (ASE, EAC, MAC, MOSS, UB, UFP, UFRN); 29-I-2008, fl. e fr., A.R.O. Ribeiro 107 (ASE, EAC, MAC, MOSS, UB, UFP, UFRN).

Densas populações são encontradas nos lagos dos diques adjacentes ao rio Apodi-Mossoró, na margem ou como aquática emergente, nos municípios de Felipe Guerra e Mossoró. Floração e frutificação na estação seca e chuvosa, janeiro-maio, agosto, outubro e dezembro.

Espécie reconhecida pelo escapo de seção transversal circular, segmentado por septos transversais que se tornam salientes quando herborizada. Os tubérculos e rizomas apresentam essência usada em perfumaria, conhecida comercialmente por "priprioca".

\subsection{Cyperus compressus L., Sp. Pl.: 46 (1753).}

Figura $2 \mathrm{c}-\mathrm{d}$

Erva cespitosa 18-42 cm. Escapo trígono, glabro, septos transversais ausentes. Lâmina foliar presente, $2,5-12,8 \mathrm{~cm} \times 1,2-2,5 \mathrm{~mm}$, herbácea, verde. Inflorescência 0,9-7 $(9,5) \times 0,8-9,8(13,4) \mathrm{cm}$; antela de grupo digitado ou espiga. Ráquis 1,8-3,4 mm compr., aparente. Espigueta 7,3-18 $\times$ 2,1-2,9 × 0,8-1 mm. Ráquila não articulada, espigueta persistente, entrenós $0,6-1 \mathrm{~mm}$ compr. Alas da ráquila ausentes ou presentes, até $0,2 \mathrm{~mm}$ compr., membranáceas, hialinas a ferrugíneas. Glumas 10-26, 2,3-2,8 × 1,6-2 mm, mucronadas ou aristadas, medianamente 8-16-nervadas, unicarenadas, decíduas, glaucas amareladas ou pardas nas margens, verdes a pardas na carena; múcron/arista 0,4-0,9 mm compr., reto(a), às vezes ligeiramente recurvado(a) até $20^{\circ}$. Estames 3 ; antera $0,4-0,7 \times 0,1-0,2 \mathrm{~mm}$; prolongamento do conectivo ausente ou presente no ápice da antera, até 0,1 mm compr., glabro. Estilete 0,9-1,4 mm compr. 
Aquênio 1,1-1,2 × 0,9-1 mm, com múcron ca. 0,1 mm compr., castanho.

Material examinado: BRASIL. RIo GRANDE do NoRTE: Apodi, Vazante da Barragem de Santa Cruz, próximo à área de recreação, 5-IV-2008, fl. e fr., R.C. Oliveira et al. 2110 (ASE, EAC, MAC, MOSS, UB, UFP, UFRN); Luís Gomes, estrada para Cachoeira do Rela, margem de afluente do Rio Apodi-Mossoró, $6^{\circ} 23^{\prime} 51$ 'S, $38^{\circ} 22^{\prime} 52^{\prime \prime} \mathrm{W}, 31-\mathrm{V}-2008$, fl. e fr., A.R.O. Ribeiro et al. 210 (ASE, EAC, MAC, MOSS, UB, UFP, UFRN); estrada para Tigre de Cima, margem de afluente do Rio Apodi-Mossoró, próximo à ponte da Baixa do Almeida, 6 ${ }^{\circ} 23^{\prime} 53^{\prime \prime} \mathrm{S}, 38^{\circ} 24^{\prime} 36^{\prime \prime} \mathrm{W}, 30-\mathrm{V}-2008$, fl. e fr., A.R.O. Ribeiro et al. 176 (ASE, EAC, MAC, MOSS, UB, UFP, UFRN); Tigre de Cima, nascente do Rio Apodi-Mossoró, 6²1'26"S, 38²7'42"W, 30-V-2008, fl. e fr., A.R.O. Ribeiro et al. 205 (ASE, EAC, MAC, MOSS, UB, UFP, UFRN); Mossoró, margem de lago próximo à Feira do Bode, próximo ao Rio ApodiMossoró, 511'58"S, 37¹9'31"W, 29-I-2008, fl. e fr., A.R.O. Ribeiro 102 (ASE, EAC, MAC, MOSS, UB, UFP, UFRN); 28-II-2008, fl. e fr., A.R.O. Ribeiro 122 (ASE, EAC, MAC, MOSS, UB, UFP, UFRN); 28-III-2008, fl. e fr., A.R.O. Ribeiro 129 (ASE, EAC, MAC, MOSS, UB, UFP, UFRN); 24-IV-2008, fl. e fr., A.R.O. Ribeiro \& A.M.S. Araújo 142 (ASE, EAC, MAC, MOSS, UB, UFP, UFRN); 21-V-2008, fl. e fr., A.R.O. Ribeiro 164 (ASE, EAC, MAC, MOSS, UB, UFP, UFRN).

Populações abundantes encontradas nos diques marginais como emergentes ou vegetando em terras não alagadas na margem do rio Apodi-Mossoró, nos municípios de Mossoró e Felipe Guerra (imediações da Cachoeira do Roncador). Floração e frutificação na estação chuvosa, janeiro-maio.

Espécie reconhecida pelas espiguetas esverdeadas arranjadas em grupos digitados ou espigas subdigitadas; 2,3-2,8 × 1,6-2 mm, mucronadas ou aristadas; múcron ou arista reto(a), raramente recurvado(a) em ângulo de até $20^{\circ}$.

1.4. Cyperus cuspidatus Kunth, F. W. H. von Humboldt, A. J. A. Bonpland \& C. S. Kunth, Nov. Gen. Sp. 1: 204 (1817).

Figura 2 e

Erva cespitosa 3,5-6,5 cm. Escapo trígono, glabro, septos transversais ausentes. Lâmina foliar presente, 1,3-1,9 $\mathrm{cm} \times 0,7-1 \mathrm{~mm}$, herbácea, verde. Inflorescência $0,8-1,9 \times 1,2-1,9 \mathrm{~cm}$; glomérulo ou espiga. Ráquis 0,2-1,5(2) mm compr., aparente. Espigueta 4,9-9 × 1,1-1,5 × 0,3-0,4 mm. Ráquila não articulada, espigueta persistente, entrenós 0,3-0,5 $\mathrm{mm}$ compr. Alas da ráquila ausentes ou presentes, até $0,2 \mathrm{~mm}$ compr., membranáceas, hialinas a amarelas. Glumas 9-25, 1-1,4×0,7-1 mm, aristadas, medianamente 2-nervadas, unicarenadas, decíduas, vináceas a pardas na margem, verdes a amareladas na carena; arista 0,5-1,2 $\mathrm{mm}$ compr., recurvada $60-90^{\circ}$. Estames 3 ; antera $0,1-0,2 \times$ ca. $0,1 \mathrm{~mm}$; prolongamento do conectivo ausente ou presente no ápice da antera, até $0,1 \mathrm{~mm}$ compr., glabro. Estilete 0,3-0,5 mm compr. Aquênio 0,5-0,6 $\times$ ca. $0,3 \mathrm{~mm}$, com múcron ca. $0,1 \mathrm{~mm}$ compr., ocráceo a castanho nas faces, castanho-escuro a negros nas arestas.

Material examinado: BRASIL. Rio GRANDE Do NORTE: Luís Gomes, estrada para Cachoeira do Rela, margem de afluente do Rio Apodi-Mossoró, 6 23'50"S, $38^{\circ} 22^{\prime} 51^{\prime \prime W}, 31-\mathrm{V}-2008$, fl. e fr., A.R.O. Ribeiro et al. 199 (ASE, EAC, MAC, MOSS, UB, UFP, UFRN).

Touceiras efêmeras encontradas em áreas mais abertas circundadas pela vegetação ripária da nascente em Tigre de Cima, município de Luís Gomes. Floração e frutificação na estação chuvosa, maio.

A espécie pode ser confundida com C. squarrosus $\mathrm{e}$ com C. uncinulatus Schrad. ex Nees, por apresentarem múcron (ou arista) recurvado.

Em C. squarrosus a ráquila é articulada na base e a espigueta cai como uma unidade; as glumas são persistentes e medialmente 6-8 nervadas. Já em C. cuspidatus, a ráquila não é articulada e a espigueta é persistente; as glumas são decíduas e medialmente 2(4)-nervadas.

A espécie C. uncinulatus, apesar de não ter sido encontrada no rio Apodi-Mossoró, tem ocorrência registrada para o Estado do Rio Grande do Norte. Portanto, são oportunos os comentários acerca da diferenciação entre estas espécies. Em C. uncinulatus as touceiras atingem $6,5-29 \mathrm{~cm}$ de altura; o entrenó da ráquila varia de 0,2-0,3 mm compr.; o androceu é 1-estaminado; a antera varia de 0,4-0,6 mm compr.; o aquênio é inteiramente castanho a ocráceo. Em C. cuspidatus as touceiras atingem $3,5-6,5 \mathrm{~cm}$ de altura; o entrenó da ráquila varia de $0,3-0,5 \mathrm{~mm}$ compr.; o androceu é 3-estaminado; a antera varia de 0,15-0,20 mm compr.; o aquênio é ocráceo a castanho nas faces, castanho-escuro a negro nas arestas.

1.5. Cyperus distans L. f., Suppl. P1.: 103 (1782).

Figura $2 \mathrm{f}$

Erva cespitosa $72-95 \mathrm{~cm}$. Escapo trígono, glabro, septos transversais ausentes. Lâmina foliar presente, 
16-57 cm ×5,3-8,4 mm, herbácea, verde. Inflorescência $15-35 \times 17-25 \mathrm{~cm}$; antela de espigas. Ráquis 9-36 mm compr., aparente. Espigueta 12-18,9 × 1,4-1,6 $\times$ 0,5-0,6 mm. Ráquila não articulada, espigueta persistente, entrenós 0,8-1,1 mm compr. Alas da ráquila presentes, ca. $0,2 \mathrm{~mm}$ compr., membranáceas, hialinas. Glumas 11-21, 1,9-2,2 × 0,9-1,1 mm, múticas, raramente mucronadas, medianamente 2-6-nervadas, unicarenadas, decíduas, castanhovináceas a pardas nas margens, frequentemente com uma faixa hialina marginal no ápice, verdes na carena; múcron até ca. $0,1 \mathrm{~mm}$ compr., reto. Estames 3 ; antera ca. $0,3 \times 0,1-0,2 \mathrm{~mm}$; prolongamento do conectivo ausente ou presente no ápice da antera, ca. $0,1 \mathrm{~mm}$ compr., glabro. Estilete 0,5-0,7 mm compr. Aquênio $1,4-1,5 \times 0,4-0,5 \mathrm{~mm}$, com múcron ca. $0,1 \mathrm{~mm}$ compr., castanho.

Material examinado: BRASIL. Rio Grande do Norte: Luís Gomes, estrada para Riacho de Santana, 2 km após Pitombeiras e 1,6 km antes do Sítio Catingueira, $6^{\circ} 19^{\prime} 52^{\prime \prime} \mathrm{S}, 38^{\circ} 24^{\prime} 22^{\prime \prime} \mathrm{W}, 31-\mathrm{V}-2008$, fl., R.C. Oliveira et al. 2222 (ASE, EAC, MAC, MOSS, UB, UFP, UFRN); estrada para Tigre de Cima, margem de afluente do rio Apodi-Mossoró, próximo à ponte da

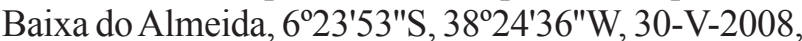
fl. e fr., A.R.O. Ribeiro et al. 177 (ASE, EAC, MAC, MOSS, UB, UFP, UFRN).

Encontrada na margem dos riachos da nascente do rio Apodi-Mossoró formando touceiras vigorosas. Importante salientar que esta espécie é frequente em ambientes mais úmidos, seja nas maiores altitudes nas serras do interior do Estado ou no litoral oriental úmido. Floração e frutificação na estação chuvosa, maio.

Reconhecida pelas touceiras vigorosas atingindo até $1 \mathrm{~m}$ de altura; espiguetas arranjadas em espigas; ráquis longa 9-36 mm compr.; entrenós da ráquila 0,8-1,1 mm compr.; glumas 1,9-2,2 × 0,9-1,1 mm, entreabertas, castanho-vináceas a pardas nas margens, frequentemente com uma faixa hialina marginal no ápice, verdes na carena, múticas ou raramente mucronadas.

1.6. Cyperus entrerianus Boeckeler, Flora 61: 139 (1878).

Figura 2 g-h

Erva cespitosa $36-72 \mathrm{~cm}$. Escapo trígono, glabro, septos transversais ausentes. Lâmina foliar presente, $10-23 \mathrm{~cm} \times 2,9-4,5 \mathrm{~mm}$, herbácea, verde. Inflorescência 3,6-6,6 × 4,8-5,9 cm; antela de glomérulos ou espigas. Ráquis 1,2-2,9 mm compr., não aparente. Espigueta 3,2-4,7 × 1,7-2 ×0,3-0,4 mm. Ráquila não articulada, espigueta persistente, entrenós $0,2-0,3 \mathrm{~mm}$ compr. Alas da ráquila ausentes ou presentes, ca. $0,1 \mathrm{~mm}$ compr., membranáceas, hialinas a vináceas. Glumas 9-16, 1,3-1,5 × 1-1,2 mm, múticas ou mucronadas, medianamente 2-3-nervadas, bicarenadas, decíduas, verdes, tornando-se pardas, pardo-amareladas ou esbranquiçadas quando desidratadas; múcron até $0,1 \mathrm{~mm}$ compr., reto. Estames 1; antera 0,6-0,9 $\times 0,1-0,2 \mathrm{~m}$; prolongamento do conectivo ausente ou presente no ápice da antera, até $0,1 \mathrm{~mm}$ compr., glabro. Estilete $0,4-0,5 \mathrm{~mm}$ compr. Aquênio 0,9-1 × 0,3-0,4 mm, com múcron ca. 0,1 mm compr., castanho a castanho-escuro.

Material examinado: BRASIL. Rio Grande do NoRTE: Felipe Guerra, Sítio do Boqueirão, próximo ao Rio Apodi-Mossoró, 536'01"S, 37²41'03"W, 26-IV-2008, fl. e fr., A.R.O. Ribeiro et al. 151 (ASE, EAC, MAC, MOSS, UB, UFP, UFRN); Governador Dix-Sept Rosado, Serrote do Boi, próximo ao Rio Apodi-Mossoró, 522'37"S, 37²9'30"W, 26-IV-2008, fl. e fr., A.R.O. Ribeiro et al. 150 (ASE, EAC, MAC, MOSS, UB, UFP, UFRN); Luís Gomes, estrada para Tigre de Cima, margem de afluente do Rio ApodiMossoró, próximo à ponte da Baixa do Almeida, $6^{\circ} 23^{\prime} 53^{\prime \prime S}, 38^{\circ} 24^{\prime} 36^{\prime \prime} \mathrm{W}, 30-\mathrm{V}-2008$, fl. e fr., A.R.O. Ribeiro et al. 178 (ASE, EAC, MAC, MOSS, UB, UFP, UFRN); Tigre de Cima, nascente do Rio ApodiMossoró, 6 $20^{\circ} 42^{\prime \prime} \mathrm{S}, 38^{\circ} 27^{\prime} 27^{\prime \prime} \mathrm{W}, 5-\mathrm{X}-2007$, fl. e fr., A.R.O. Ribeiro et al. 10 (ASE, EAC, MAC, MOSS, UB, UFP, UFRN).

Encontrada nas imediações da nascente do rio Apodi-Mossoró em Luís Gomes e também em Felipe Guerra, ocupando preferencialmente terrenos pedregosos. Em Governador Dix-Sept Rosado foi observada em relevo mais plano nas imediações dos lagos formados pelos diques marginais. Floração e frutificação na estação seca e chuvosa, abril, maio e outubro. Durante o mês de outubro foi observada somente em Luís Gomes.

A espécie pode ser confundida com $C$. surinamensis. Em C. entrerianus os escapos são glabros; as espiguetas estão em glomérulos esféricos, hemisféricos ou em espigas globosas; a ráquis mede 1,2-2,9 mm compr.; o aquênio mede $0,9-1 \mathrm{~mm}$ compr. Em $C$. surinamenis os escapos são retrorsamente escabros, raramente glabros; as espiguetas estão em fascículos seriados; a ráquis mede $0,3-0,5 \mathrm{~mm}$ compr.; o aquênio mede $0,6-0,8 \mathrm{~mm}$ compr.

Também são frequentemente confundidas as espécies C. entrerianus e C. luzulae (L.) Rottb. ex 
Retz. A espécie C. luzulae, apesar de não ter sido observada no rio Apodi-Mossoró, tem ocorrência registrada para o Estado do Rio Grande do Norte. Portanto, são pertinentes os comentários sobre as diferenças morfológicas entre estas duas espécies. Em C. luzulae, as espiguetas estão em espigas cuja ráquis é longa, medindo 3,5-12 mm compr.; as glumas são alvas tornando-se pardas quando herborizadas; as anteras variam de $0,4-0,5 \mathrm{~mm}$ compr. Em C. entrerianus as espiguetas estão em glomérulos esféricos, hemisféricos ou em espigas globosas cuja ráquis é curta, medindo 1,2-2,9 mm compr; as glumas são esverdeadas, tornando-se pardas quando desidratadas; as anteras variam de $0,6-0,9 \mathrm{~mm}$ compr.

Há divergências quanto à classificação da espécie C. entrerianus. Os trabalhos de Denton (1978) e Araújo \& Longhi-Wagner (1996) consideram-na como uma variedade de C. luzulae. O presente trabalho seguiu a classificação estabelecida por Kükenthal (1956), Tucker (1994), Luceño et al. (1997) e Guarise \& Vegetti (2007), que elevam C. entrerianus ao nível de espécie. Assim como Tucker (1994), verificou-se distribuição alopátrica entre as duas espécies, além de diferenças morfológicas significativas. No Rio Grande do Norte, C. entrerianus distribui-se pelo agreste e sertão, tanto em áreas de caatinga, como nas formações florestais relictuais presentes nas maiores altitudes. A ocorrência de $C$. luzulae foi observada somente no litoral úmido oriental, em uma área de Cerrado, no município de Canguaretama.

\subsection{Cyperus esculentus L., Sp. Pl.: 45 (1753).} Figura 2 i

Erva cespitosa $37-60 \mathrm{~cm}$. Escapo com seção transversal triangular, glabro, septos transversais ausentes. Lâmina foliar presente, $12-35 \mathrm{~cm} \times$ 2,4-4,5 $\mathrm{mm}$, herbácea, verde. Inflorescência 5-8 $\times 3-4 \mathrm{~cm}$; antela de espigas, raramente de grupos digitados. Ráquis 0,5-10 mm compr., aparente. Espigueta 6,3-22 × 1,8-2,8 × 0,4-0,5 mm. Ráquila não articulada, espigueta persistente, entrenós 0,6-0,8 $\mathrm{mm}$ compr. Alas da ráquila presentes, ca. 0,2 mm compr., membranáceas, ferrugíneas. Glumas 7-30, 2,8-3,4 × 1,4-1,6 mm, múticas ou mucronadas, medianamente 6-10-nervadas, unicarenadas, persistentes, pardas a ocráceas nas margens, verdes, às vezes pardas na carena; múcron até $0,3 \mathrm{~mm}$ compr., reto. Estames 3; antera $1,1-1,8 \times 0,1-0,2 \mathrm{~mm}$; prolongamento do conectivo ausente ou presente no ápice da antera, até $0,1 \mathrm{~mm}$ compr., glabro. Estilete 0,9-1,1 mm compr.; Aquênio
$(1,1) 1,3-1,5(1,6) \times 0,3-0,6(0,8) \mathrm{mm}$, castanho, com múcron ca. $0,1 \mathrm{~mm}$ compr.

Material examinado: BRASIL. Rio GRANDE Do Norte: Governador Dix-Sept Rosado, Serrote do Boi, próximo ao Rio Apodi-Mossoró, 522'37"S, 37'29'30"W, 26-IV-2008, fl., A.R.O. Ribeiro et al. 213 (ASE, EAC, MAC, MOSS, UB, UFP, UFRN); Mossoró, margem do Rio Apodi-Mossoró, próximo ao Cartódromo, 5¹1'56"S, 37¹9'42"W, 21-V-2008, fl., A.R.O. Ribeiro 170 (ASE, EAC, MAC, MOSS, UB, UFP, UFRN).

Encontrada somente em áreas com interferência antrópica em Governador Dix-Sept Rosado e em Mossoró. Floração e frutificação na estação chuvosa, abril e maio.

A espécie pode ser confundida com C. rotundus, por apresentar glumas e espiguetas persistentes. Em C. esculentus, as glumas são pardas a ocráceas nas margens, verdes, às vezes pardas na carena. Já em C. rotundus, as glumas são vináceas, raramente pardovináceas nas margens, verdes na carena.

Não foram encontrados aquênios no material examinado. Para descrição deste órgão, foram utilizados os dados obtidos por Tucker (1994).

1.8. Cyperus iria L., Sp. Pl.: 45 (1753).

Figura $2 \mathrm{j}$

Erva cespitosa $39-82 \mathrm{~cm}$. Escapo trígono, glabro, septos transversais ausentes. Lâmina foliar presente, 9-27 $\mathrm{cm} \times 3,1-5,1 \mathrm{~mm}$, herbácea, verde. Inflorescência 7,1-13 × 6,7-15 cm; antela de espigas. Ráquis 1,2-33 mm compr., aparente. Espigueta 4,5-9,5 × 1,5-2 × 0,5-0,7 mm. Ráquila não articulada, espigueta persistente, entrenós $0,5-0,7 \mathrm{~mm}$ compr. Alas da ráquila ausentes ou presentes, ca. $0,1 \mathrm{~mm}$ compr., membranáceas, hialinas a vináceas. Glumas 6-17, 1,2-1,6 × 1,4-1,8 mm, mucronadas, raramente múticas, medianalmente 2-4-nervadas; unicarenadas, decíduas, amarelas a pardo-amareladas nas margens, com faixa hialina marginal no ápice, verdes na carena; múcron 0,1-0,2 mm compr., reto. Estames 2; antera $0,3-0,4(0,7) \times 0,1-0,2 \mathrm{~mm}$; prolongamento do conectivo ausente ou presente no ápice da antera, até $0,1 \mathrm{~mm}$ compr., glabro. Estilete 0,1-0,2 mm compr. Aquênio 1,1-1,2 × 0,4-0,6 mm, com múcron ca. $0,1 \mathrm{~mm}$ compr., castanho a ferrugíneo.

Material examinado: BRASIL. Rio Grande do NoRTE: Luís Gomes, estrada para Cachoeira do Rela, margem de afluente do Rio Apodi-Mossoró, 6 23'51"S, $38^{\circ} 22^{\prime} 52^{\prime \prime} \mathrm{W}, 31-\mathrm{V}-2008$, fl. e fr., A.R.O. Ribeiro et al. 
208 (ASE, EAC, MAC, MOSS, UB, UFP, UFRN); estrada para Tigre de Cima, margem de afluente do Rio Apodi-Mossoró, próximo à ponte da Baixa do Almeida., 6²3'53"S, 38²4'36"W, 30-V-2008, fl. e fr., A.R.O. Ribeiro et al. 172 (ASE, EAC, MAC, MOSS, UB, UFP, UFRN); Mossoró, margem de lago próximo à Feira do Bode, próximo ao Rio Apodi-Mossoró, 5011'58"S, 37019'31"W, 29-I-2008, fl. e fr., A.R.O. Ribeiro 101 (ASE, EAC, MAC, MOSS, UB, UFP, UFRN); 28-II-2008, fl. e fr., A.R.O. Ribeiro 119 (ASE, EAC, MAC, MOSS, UB, UFP, UFRN); 28-III-2008, fl. e fr., A.R.O. Ribeiro 128 (ASE, EAC, MAC, MOSS, UB, UFP, UFRN); 24-IV-2008, fl. e fr., A.R.O. Ribeiro \& A. M. S. Araújo 139 (ASE, EAC, MAC, MOSS, UB, UFP, UFRN); 21-V-2008, fl. e fr., A.R.O. Ribeiro 160 (ASE, EAC, MAC, MOSS, UB, UFP, UFRN); margem do Rio Apodi-Mossoró, próximo ao Cartódromo, 511'56"S, 37¹9'42"W, 24-IV-2008, fl. e fr., A.R.O. Ribeiro \& A. M. S. Araújo 149 (ASE, EAC, MAC, MOSS, UB, UFP, UFRN).

Observada na margem dos riachos da nascente do rio Apodi-Mossoró em Luís Gomes e também em Mossoró, na margem dos lagos dos diques marginais. Floração e frutificação na estação chuvosa, janeiromaio.

Espécie reconhecida pelas espiguetas medindo 4,5-9,5 × 1,5-2 × 0,5-0,7 mm, arranjadas em espigas; glumas 1,2-1,6 × 1,4-1,8 mm, largamente obovais a muito largamente obovais, amarelas a pardoamareladas nas margens, com faixa hialina marginal no ápice, verdes na carena.

1.9. Cyperus laxus Lam., Tabl. Encycl. 1: 146 (1791). Figura $2 \mathrm{k}$

Erva cespitosa 30-65 $\mathrm{cm}$. Escapo trígono, glabro, raramente antrorsamente escabro no ápice, septos transversais ausentes. Lâmina foliar presente, 4,5-18 $\mathrm{cm} \times 2,9-6,1 \mathrm{~mm}$, herbácea, verde. Inflorescência 4,2-12,6 × 6,5-18,7 cm; antela de grupos digitados ou espigas. Ráquis $0,4-1,5 \mathrm{~mm}$ compr., aparente. Espigueta 5-10 × 1,8-2,2 × 0,9-1,1 mm. Ráquila não articulada, espigueta persistente, entrenós 0,6-0,8 $\mathrm{mm}$ compr. Alas da ráquila ausentes ou presentes, até $0,2 \mathrm{~mm}$ compr., membranáceas, hialinas a vináceas. Glumas 6-14, 1,2-1,4 × 1,6-2,1 mm, aristada a mucronada, medianamente 8-14-nervadas; unicarenadas, decíduas, pardas a pardo-amareladas, às vezes com manchas ferrugíneas nas margens, verdes a pardas na carena; múcron 0,3-0,7 mm compr., reto ou recurvado até $45^{\circ}$. Estames 3 ; antera $0,5-0,7 \times 0,1-0,2 \mathrm{~mm}$; prolongamento do conectivo presente no ápice da antera, 0,1-0,2 mm compr., antrorsamente escabro. Estilete 0,1-0,2 mm compr. Aquênio 1,3-1,5 × 0,8-1 mm, com múcron ca. 0,1 mm compr., castanho a castanho-escuro, superfície reticulada, papilosa, parcialmente exposto pela gluma.

Material examinado: BRASIL. Rio GRANDE Do NorTE: Luís Gomes, estrada para Cachoeira do Rela, margem de afluente do Rio Apodi-Mossoró, 6 $233^{\prime} 50^{\prime \prime} \mathrm{S}$, $38^{\circ} 22^{\prime} 51^{\prime \prime} \mathrm{W}, 31-\mathrm{V}-2008$, fl. e fr., A.R.O. Ribeiro et al. 206 (ASE, EAC, MAC, MOSS, UB, UFP, UFRN); Tigre de Cima, nascente do Rio Apodi-Mossoró, $6^{\circ} 22^{\prime} 88^{\prime \prime} \mathrm{S}, 38^{\circ} 28^{\prime} 54^{\prime \prime} \mathrm{W}, 24-\mathrm{VIII}-2007$, fl. e fr., A.R.O. Ribeiro et al. 4 (ASE, EAC, MAC, MOSS, UB, UFP, UFRN); 621'42"S, 38²7'49"W, 30-V-2008, fl. e fr., A.R.O. Ribeiro et al. 195 (ASE, EAC, MAC, MOSS, UB, UFP, UFRN).

Sempre associada à borda de mata ou ambientes sombreados na nascente do rio Apodi-Mossoró em Luís Gomes. Floração e frutificação na estação seca e chuvosa, maio e agosto.

Espécie reconhecida pelas espiguetas com $5-10 \times 1,8-2,2 \times 0,9-1,1 \mathrm{~mm}$, arranjadas em grupo digitado ou espiga subdigitada; ráquis $0,4-1,5 \mathrm{~mm}$ compr.; glumas 1,2-1,4 × 1,6-2,1 mm, aristada a mucronada, pardas a pardo-amareladas, às vezes com manchas ferrugíneas nas margens, verdes a pardas na carena; múcron 0,3-0,7 mm compr., reto ou recurvado até $45^{\circ}$; prolongamento do conectivo antrorsamente escabro; aquênio 1,3-1,5 mm compr. Foi observado escapo antrorsamente escabro nos ângulos na porção apical em A.R.O. Ribeiro et al. 4.

1.10. Cyperus ligularis L., Amoen. Acad. 5: 31 (1760).

Figura 21

Erva cespitosa 45-132 cm. Escapo trígono, glabro, septos transversais ausentes. Lâmina foliar presente, $17-93 \mathrm{~cm} \times 7,3-14,1 \mathrm{~mm}$, cartácea, glauca. Inflorescência 4,1-14,7 × 5,6-17,3 cm; antela de espigas. Ráquis 3,6-14,2 mm compr., não aparente. Espigueta 3,7-7,9 × 1,4-1,7 × 0,7-0,8 mm. Ráquila articulada na base, espigueta caindo como uma unidade, entrenós $0,4-0,8 \mathrm{~mm}$ compr. Alas da ráquila presentes, 0,4-0,8 mm compr., membranáceas, pardas, pardo-esverdeadas ou hialinas, às vezes com manchas vináceas. Glumas 5-8, 2,2-2,5 × 1,2-1,7 mm, múticas, raramente mucronadas, medianamente 8-14-nervadas, unicarenadas, persistentes, pardo-vináceas, às vezes pardas nas margens, verdes na carena; múcron até $0,1 \mathrm{~mm}$ compr., reto. Estames 3; antera 0,4-0,6 $\times 0,1-0,2 \mathrm{~mm}$; prolongamento do conectivo 
ausente ou presente no ápice da antera, ca. $0,1 \mathrm{~mm}$ compr., glabro. Estilete 0,4-0,6 mm compr. Aquênio 1,2-1,5 × 0,5-0,7 mm, com múcron ca. $0,1 \mathrm{~mm}$ compr., castanho-alaranjado a castanho.

Material examinado: BRASIL. Rio Grande do NoRTE: Governador Dix-Sept Rosado, Sítio Pedrinha, margem do Rio Apodi-Mossoró, 5¹9'47"S, 37²7'42"W, 22-II-2008, fl. e fr., A.R.O. Ribeiro et al. 111 (ASE, EAC, MAC, MOSS, UB, UFP, UFRN); Mossoró, margem de lago próximo à Feira do Bode, próximo

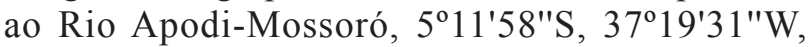
19-X-2007, fl. e fr., A.R.O. Ribeiro 19 (ASE, EAC, MAC, MOSS, UB, UFP, UFRN); 23-XI-2007, fl. e fr., A.R.O. Ribeiro 81 (ASE, EAC, MAC, MOSS, UB, UFP, UFRN); 29-I-2008, fl. e fr., A.R.O. Ribeiro 104 (ASE, EAC, MAC, MOSS, UB, UFP, UFRN); 28-II-2008, fl. e fr., A.R.O. Ribeiro 117 (ASE, EAC, MAC, MOSS, UB, UFP, UFRN); 28-III-2008, fl. e fr., A.R.O. Ribeiro 126 (ASE, EAC, MAC, MOSS, UB, UFP, UFRN); 24-IV-2008, fl. e fr., A.R.O. Ribeiro \& A.M.S. Araújo 135 (ASE, EAC, MAC, MOSS, UB, UFP, UFRN); 21-V-2008, fl. e fr., A.R.O. Ribeiro 156 (ASE, EAC, MAC, MOSS, UB, UFP, UFRN); margem direita do Rio Mossoró, 10-X-1992, fl. e fr., G.G. Silva \& S. Batista s.n. (MOSS10154); Ponte de Pedra, Rio Apodi-Mossoró, 511'15"S, 37²0'39"W, 11-I-2008, fl. e fr., A.R.O. Ribeiro et al. 110 (ASE, EAC, MAC, MOSS, UB, UFP, UFRN); Rio Mossoró, atrás do Cartódromo, 5 ${ }^{\circ} 11^{\prime} 56^{\prime \prime} \mathrm{S}, 37^{\circ} 19^{\prime} 42^{\prime \prime} \mathrm{W}, 21-\mathrm{IX}-2007$, fl. e fr., A.R.O. Ribeiro 8 (ASE, EAC, MAC, MOSS, UB, UFP, UFRN).

Touceiras vigorosas e rústicas, espécie encontrada preferencialmente em ambientes mais quentes ou salinos, nos municípios de Mossoró e Governador Dix-Sept Rosado. Ocorre nos diques marginais e nas adjacências do leito do rio Apodi-Mossoró. Persiste mesmo em ambientes alterados. Floração e frutificação na estação seca e chuvosa, janeiro-maio e setembrodezembro.

Espécie reconhecida pelas lâminas foliares cartáceas, glaucas; espiguetas vináceas a pardovináceas, arranjadas em densas espigas; ráquis oculta pelas espiguetas.

1.11. Cyperus odoratus L., Sp. Pl.: 46 (1753). Figura $2 \mathrm{~m}-\mathrm{n}$

Erva cespitosa $32-113 \mathrm{~cm}$. Escapo trígono, glabro, septos transversais ausentes. Lâmina foliar presente, 5,5-72,7 $\mathrm{cm} \times 1,8-11,4 \mathrm{~mm}$, herbácea, verde. Inflorescência 6,3-18,6 × 5,5-16,7 cm; antela de espigas. Ráquis 3,2-11,5 mm compr., aparente.
Espigueta $13-23 \times 0,9-1,4 \times 0,6-1 \mathrm{~mm}$. Ráquila articulada na base e em todos os nós, espigueta desarticulando-se em unidades constituídas de um entrenó da ráquila, uma gluma e um aquênio, entrenós 1,3-2 mm compr. Alas da ráquila presentes, 0,6-1,3 mm compr., esponjosas e quebradiças, pardoamareladas a ocráceas tornando-se membranáceas nas margens. Glumas 6-14, 2,3-3,1 × 1,3-2,5 mm, múticas ou mucronadas, medianamente 4-8-nervadas, unicarenadas, persistentes, pardas, ferrugíneas ou vináceas nas margens, verdes na carena; múcron até $0,1 \mathrm{~mm}$ compr., reto. Estames 3; antera $0,4-0,7 \times 0,1-0,2 \mathrm{~mm}$; prolongamento do conectivo ausente ou presente no ápice da antera, até $0,1 \mathrm{~mm}$ compr., glabro. Estilete 0,5-0,7 mm compr. Aquênio $1,5-1,8 \times 0,5-0,6 \mathrm{~mm}$, com múcron ca. $0,1 \mathrm{~mm}$ compr., castanho a castanho-escuro.

Material examinado: BRASIL. Rio Grande do Norte: Luís Gomes, $10 \mathrm{~km}$ após a Vila Aparecida, em direção a Tigre de Cima, 6ํำ $21^{\prime} 05^{\prime \prime} \mathrm{S}, 38^{\circ} 25^{\prime} 09^{\prime \prime} \mathrm{W}$, 28-VIII-2008, fl. e fr., R.C. Oliveira et al. 2235 (ASE, EAC, MAC, MOSS, UB, UFP, UFRN); estrada para Tigre de Cima, margem de afluente do Rio ApodiMossoró, próximo à ponte da Baixa do Almeida., $6^{\circ} 23^{\prime} 53^{\prime \prime} \mathrm{S}, 38^{\circ} 24^{\prime} 36^{\prime \prime} \mathrm{W}, 30-\mathrm{V}-2008$, fl. e fr., A.R.O. Ribeiro et al. 173 (ASE, EAC, MAC, MOSS, UB, UFP, UFRN); Mossoró, margem de lago próximo à Feira do Bode, próximo ao Rio Apodi-Mossoró, $5^{\circ} 11^{\prime} 58^{\prime \prime} \mathrm{S}, 37^{\circ} 19^{\prime} 31 " \mathrm{~W}, 19-\mathrm{X}-2007$, fl. e fr., A.R.O. Ribeiro 18 (ASE, EAC, MAC, MOSS, UB, UFP, UFRN); 23-XI-2007, fl. e fr., A.R.O. Ribeiro 82 (ASE, EAC, MAC, MOSS, UB, UFP, UFRN); 29-I-2008, fl. e fr., A.R.O. Ribeiro 105 (ASE, EAC, MAC, MOSS, UB, UFP, UFRN); 28-II-2008, fl. e fr., A.R.O. Ribeiro 118 (ASE, EAC, MAC, MOSS, UB, UFP, UFRN); 28-III-2008, fl. e fr., A.R.O. Ribeiro 127 (ASE, EAC, MAC, MOSS, UB, UFP, UFRN); 24-IV-2008, fl. e fr., A.R.O. Ribeiro \& A.M.S. Araújo 137 (ASE, EAC, MAC, MOSS, UB, UFP, UFRN); 21-V-2008, fl. e fr., A.R.O. Ribeiro 158 (ASE, EAC, MAC, MOSS, UB, UFP, UFRN); próximo à Ponte de Ferro, Rio Mossoró, $5^{\circ} 11^{\prime} 15^{\prime \prime} \mathrm{S}, 37^{\circ} 20^{\prime} 39^{\prime \prime} \mathrm{W}, 11-\mathrm{I}-2008$, fl. e fr., A.R.O. Ribeiro \& A.S.Silva 96 (ASE, EAC, MAC, MOSS, UB, UFP, UFRN).

Amplamente distribuída, desde a nascente até o município de Mossoró, seja nas margens do rio Apodi-Mossoró ou nos diques marginais. Floração e frutificação na estação seca e chuvosa, janeiro-maio, agosto, outubro e novembro.

Espécie reconhecida pela ráquila articulada na base e em todos os nós; espiguetas partindo-se em 
diásporos constituídos de uma gluma, um aquênio e um entrenó da ráquila; alas da ráquila esponjosas e quebradiças, tornando-se membranáceas nas margens.

\subsection{Cyperus rotundus L., Sp. P1.: 45 (1753).}

Figura 20

Erva cespitosa 14-42 cm. Escapo trígono, glabro, septos transversais ausentes. Lâmina foliar presente, 3,5-16,1 cm × 1,9-4,2 $\mathrm{mm}$, herbácea, verde. Inflorescência 4,1-10,2 × 3,8-8,5 cm; antela de espigas. Ráquis 1,9-5,4 mm compr., aparente. Espigueta 11-23 × 1,3-1,8 × 0,6-0,7 mm. Ráquila não articulada, espigueta persistente, entrenós 0,9-1,4 $\mathrm{mm}$ compr. Alas da ráquila presentes, 0,3-0,4 mm compr., membranáceas, hialinas. Glumas 12-26, 2,8-3,7 × 1,6-2,4 mm, múticas ou mucronadas, medianamente 4-8-nervadas, unicarenadas, persistentes, vináceas, raramente pardo-vináceas nas margens, verdes na carena; múcron até $0,1 \mathrm{~mm}$ compr., reto. Estames 3; antera 1,2-1,7 $\times 0,1-0,2 \mathrm{~mm}$; prolongamento do conectivo ausente ou presente no ápice da antera, até $0,1 \mathrm{~mm}$ compr., glabro. Estilete 1,2-1,8 mm compr. Aquênio 1,4-1,6 × 0,7-0,8 mm, com múcron ca. $0,1 \mathrm{~mm}$ compr., castanho a castanho-amarelado.

Material examinado: BRASIL. Rio GRANDE Do NoRTE: Governador Dix-Sept Rosado, Sítio Pedrinha, margem do Rio Apodi-Mossoró, 5¹9'47"S, 37²7'42"W, 22-II-2008, fl., A.R.O. Ribeiro et al. 115 (ASE, EAC, MAC, MOSS, UB, UFP, UFRN); Mossoró, margem de lago, próximo à Feira do Bode, próximo ao Rio Apodi-Mossoró, 5 $11^{\prime} 58^{\prime \prime} \mathrm{S}, 37^{\circ} 19^{\prime} 31^{\prime \prime} \mathrm{W}, 28-\mathrm{III}-2008$, fl., A.R.O. Ribeiro 131 (ASE, EAC, MAC, MOSS, UB, UFP, UFRN); 21-V-2008, fl. e fr., A.R.O. Ribeiro 161 (ASE, EAC, MAC, MOSS, UB, UFP, UFRN); margem do Rio Apodi-Mossoró, próximo ao Cartódromo, 5¹1'56"S, 37019'42"W, 24-IV-2008, fl., A.R.O. Ribeiro \& A.M.S. Araújo 143 (ASE, EAC, MAC, MOSS, UB, UFP, UFRN); próximo à Ponte de Ferro, Rio Mossoró, 511'15"S, 37²0'39"W, 11-I-2008, fl., A.R.O. Ribeiro \& A.S. Silva 95 (ASE, EAC, MAC, MOSS, UB, UFP, UFRN).

Espécie sempre associada à perturbação antrópica. Coletada em Mossoró e Governador Dix-Sept Rosado. Floração e frutificação na estação chuvosa, janeiromaio.

A espécie pode ser confundida com C. esculentus (ver comentários sob 1.7). Ocorrência sempre associada à perturbação antrópica. Em A.R.O. Ribeiro 161 foi encontrado tubérculo. Aquênios raramente presentes nos materiais examinados.
Mundialmente conhecida pelo nome de "purple nutsedge" e no Brasil por "tiririca", C. rotundus é considerada a planta daninha mais nociva nas regiões tropicais e subtropicais do planeta, infestando quase todas as principais culturas (Dor \& Hershenhorn 2013, FAO 2013). De acordo com Bendixen \& Nandihalli (1987) sua relevância como planta daninha já foi citada em pelo menos 52 culturas e mais de 90 países.

A agressividade e ampla distribuição nas infestações de $C$. rotundus podem ser atribuídas à propagação vegetativa por rizomas e tubérculos, fixação do carbono pela via fotossintética $\mathrm{C} 4$ e tolerância a solos úmidos e temperaturas elevadas (Bendixen \& Nandihalli 1987). Compostos aleloqúimicos presentes nos tubérculos aumentam o potencial competitivo de C. rotundus, inibindo ou reduzindo a germinação de sementes de outras espécies (Singh et al. 2009). É comum a persistência de $C$. rotundus em áreas tratadas repetidamente com herbicidas (FAO 2013). A movimentação do solo no sistema convencional de manejo também não é eficaz ao controle e ainda favorece a propagação pela fragmentação e deslocamento dos tubérculos, originando inúmeras plântulas a cada operação de preparo do solo (Cordeiro et al. 2006).

Embora efeitos negativos sejam relevantes na agricultura, inúmeras qualidades fitoterápicas de C. rotundus foram validadas pela ciência moderna (Sivapalan 2013). Distintos compostos atuam como princípios ativos e podem ser extraídos dos rizomas, tubérculos, folhas e raízes, entre os quais óleos essenciais, alcaloides, flavonoides, taninos, amido e sesquiterpenoides (Sivapalan 2013). As propriedades farmacológicas incluem ações antiinflamatória, antidiabética, antidiarreica, citoprotetora, antimutagênica, antimicrobiana, antioxidante, antipirética e analgésica (Ahmad et al. 2012, Jahan et al. 2012, Sivapalan 2013).

\subsection{Cyperus squarrosus L., Cent. P1. II: 6 (1756).}

Figura $2 \mathrm{p}$

Erva cespitosa 7-29 cm. Escapo trígono, glabro, septos transversais ausentes. Lâmina foliar presente, $3,5-13 \mathrm{~cm} \times 1,5-2,8 \mathrm{~mm}$, herbácea, verde. Inflorescência 1,5-4,7 × 1,3-4,5 cm; 2 ordens; antela de espigas. Ráquis 1,3-7,6 mm compr., aparente ou não. Espigueta 2,1-6 × 0,9-1,5 × 0,2-0,4 mm. Ráquila articulada na base, espigueta desarticulando-se com uma unidade, entrenós 0,3-0,4 mm compr. Alas da ráquila ausentes, raramente presentes, até $0,1 \mathrm{~mm}$ compr., membranáceas, hialinas a vináceas. Glumas 
$5-14,1,2-1,7 \times 0,6-0,8 \mathrm{~mm}$, aristadas, medianamente 6-8-nervadas, unicarenadas, persistentes, esverdeadas, pardas, alaranjadas a vináceas nas margens e carena; arista $0,5-1,6 \mathrm{~mm}$ compr., recurvada $45-100^{\circ}$. Estames 1; antera 0,2-0,3 $\times$ ca. $0,1 \mathrm{~mm}$; prolongamento do conectivo ausente ou presente no ápice da antera, até $0,1 \mathrm{~mm}$ compr., glabro. Estilete $0,3-0,4 \mathrm{~mm}$ compr. Aquênio 0,7-0,8 $\times$ 0,2-0,3 mm, pardo a ferrugíneo, com múcron ca. $0,1 \mathrm{~mm}$ compr.

Material examinado: BRASIL. Rio GRANDE Do NoRTE: Felipe Guerra, Cachoeira do Roncador, próximo ao Rio Apodi-Mossoró, 5³4'35"S, 37040'33"W, 26-IV-2008, fl. e fr., A.R.O. Ribeiro et al. 152 (ASE, EAC, MAC, MOSS, UB, UFP, UFRN); Luís Gomes, estrada para Tigre de Cima, margem de afluente do Rio Apodi-Mossoró, próximo à ponte da Baixa do Almeida, 6 ${ }^{\circ} 23^{\prime} 53^{\prime \prime} \mathrm{S}, 38^{\circ} 24^{\prime} 36^{\prime \prime} \mathrm{W}, 30-\mathrm{V}-2008$, fl. e fr., A.R.O. Ribeiro et al. 181 (ASE, EAC, MAC, MOSS, UB, UFP, UFRN); Tigre de Cima, nascente do Rio Apodi-Mossoró, 6² 1 '26"S, 38²7'42"W, 30-V-2008, fl. e fr., A.R.O. Ribeiro et al. 204 (ASE, EAC, MAC, MOSS, UB, UFP, UFRN); Mossoró, margem do Rio Apodi-Mossoró, próximo ao Cartódromo, 511'56"S, 37¹9'42"W, 24-IV-2008, fl. e fr., A.R.O. Ribeiro \& A.M.S. Araújo 147 (ASE, EAC, MAC, MOSS, UB, UFP, UFRN); 21-V-2008, fl. e fr., A.R.O. Ribeiro 168 (ASE, EAC, MAC, MOSS, UB, UFP, UFRN).

Encontrada em Luís Gomes na margem de riachos periódicos que compõem a nascente do rio ApodiMossoró e no município de Mossoró, ocorrendo na margem do rio ou nos diques marginais. Floração e frutificação na estação chuvosa, abril e maio.

Espécie pode ser confundida com C. cuspidatus (ver comentários sob 1.4). Apresenta odor característico, mesmo herborizada, semelhante ao fruto do mamoeiro (Carica papaya L.).

1.14. Cyperus surinamensis Rottb., Descr. Icon. Rar. Pl.: 35 (1773).

Figura 2 q-r

Erva cespitosa $35-101 \mathrm{~cm}$. Escapo trígono, retrorsamente escabro a glabro nas porções basal e mediana, retrorsamente escabro, raramente glabro na porção apical, septos transversais ausentes. Lâmina foliar presente, 9-27 cm $\times 3,1-6,5 \mathrm{~mm}$, herbácea, verde. Inflorescência 2,7-11,4 × 2,1-15 cm; antela de fascículos seriados. Ráquis $0,3-0,5 \mathrm{~mm}$ compr., aparente ou não. Espigueta 3,5-10,7 × 1,7-2,2 × 0,2-0,3 mm. Ráquila não articulada, espigueta persistente, entrenós 0,2-0,3 mm compr. Alas da ráquila ausentes ou presentes, até $0,1 \mathrm{~mm}$ compr., membranáceas, hialinas a ferrugíneas. Glumas 13-36, 1,2-1,5 × 0,8-1,1 mm, múticas ou mucronadas, medianamente 2-3-nervadas, bicarenadas, decíduas, pardo-esverdeadas, amareladas a alaranjadas nas margens e na carena; múcron até $0,1 \mathrm{~mm}$ compr., reto. Estames 1; antera 0,4-0,6 $\times$ 0,1-0,2 $\mathrm{mm}$; prolongamento do conectivo presente no ápice da antera, 0,10-0,15 mm compr., glabro. Estilete 0,3-0,4 mm compr. Aquênio 0,6-0,8 $\times$ 0,2-0,4 mm, com múcron ca. $0,1 \mathrm{~mm}$ compr., castanho a castanhoalaranjado.

Material examinado: BRASIL. Rio Grande do NorTE: Luís Gomes, $10 \mathrm{~km}$ após a Vila Aparecida, em direção a Tigre de Cima, 6 $21^{\circ} 05^{\prime \prime} \mathrm{S}, 38^{\circ} 25^{\prime} 09^{\prime \prime} \mathrm{W}$, 28-VIII-2008, fl. e fr., R.C. Oliveira et al. 2234 (ASE, EAC, MAC, MOSS, UB, UFP, UFRN); estrada para Cachoeira do Rela, margem de afluente do Rio Apodi-Mossoró, 6²3'51"S, 38²2'52"W, 31-V-2008, fl. e fr., A.R.O. Ribeiro et al. 207 (ASE, EAC, MAC, MOSS, UB, UFP, UFRN); estrada para Tigre de Cima, margem de afluente do Rio Apodi-Mossoró, próximo à ponte da Baixa do Almeida, $6^{\circ} 23^{\prime} 53^{\prime \prime} \mathrm{S}, 38^{\circ} 24^{\prime} 36^{\prime \prime} \mathrm{W}$, 30-V-2008, fl. e fr., A.R.O. Ribeiro et al. 214 (ASE, EAC, MAC, MOSS, UB, UFP, UFRN); Mossoró, margem de lago próximo à Feira do Bode, próximo ao Rio Apodi-Mossoró, 5¹1'58"S, 37º19'31"W, 29-I-2008, fl. e fr., A.R.O. Ribeiro 99 (ASE, EAC, MAC, MOSS, UB, UFP, UFRN); 28-III-2008, fl. e fr., A.R.O. Ribeiro 130 (ASE, EAC, MAC, MOSS, UB, UFP, UFRN); 24-IV-2008, fl. e fr., A.R.O. Ribeiro \& A.M.S. Araújo 140 (ASE, EAC, MAC, MOSS, UB, UFP, UFRN); 21-V-2008, fl. e fr., A.R.O. Ribeiro 157 (ASE, EAC, MAC, MOSS, UB, UFP, UFRN).

Em Luís Gomes forma populações na margem de riachos periódicos que compõem a nascente do rio Apodi-Mossoró. Em Mossoró foi encontrada na margem do rio ou nos diques marginais. Floração e frutificação na estação chuvosa, janeiro-maio.

Espécie pode ser confundida com C. entrerianus (ver comentários sob 1.6). A disposição das espiguetas na ráquis é peculiar. O conjunto é definido como fascículo seriado por Guarise \& Vegetti (2007) e constitui-se em um importante caráter taxonômico. Neste tipo de inflorescência, as espiguetas dispõem-se em arranjo dístico, com as faces laterais aproximadamente paralelas, voltadas umas paras as outras.

Em A.R.O. Ribeiro et al. 207 há escapos levemente escabros e também escapos glabros na mesma touceira, comprovando a variação do caráter dentro da espécie. Conforme Façanha et al. (2007), C. surinamensis apresenta eficiência na fito extração de chumbo, cromo e zinco. 
2. Eleocharis R.Br., Prodr. Fl. Nov. Holl.: 224 (1810).

Lâmina foliar ausente. Contralígula ausente. Brácteas de $1^{\text {a }}$ ordem ausentes. Inflorescência terminal, simples, uniespiculada. Espigueta solitária na inflorescência, normalmente desenvolvida, aparente. Glumas presentes, 10-várias, espiraladamente arranjadas. Flores bissexuadas, periantadas. Estilete com base persistente; estigmas 2-3, fimbriados. Aquênio lenticular ou trígono, superfície lisa a reticulada. Estilopódio presente. Cerdas periânticas presentes. Hipogínio ausente.

Chave para identificação das espécies de Eleocharis do rio Apodi-Mossoró

1. Escapo 3,3-7 mm larg., seção transversal triangular; espigueta 20-43 $\times$ 4-6 mm; gluma 3,2-3,8 $\times 2,3-2,7 \mathrm{~mm}$, espatuliforme a oblonga; aquênio $1,7-1,8 \times 1,4-1,5 \times 0,8-0,9 \mathrm{~mm}$...... E. mutata

1. Escapo 0,2-1 mm larg., seção transversal circular ou quadrangular; espigueta 2,4-8,5 $\times$ 1,8-3,1 mm; gluma 1,4-2,3 $\times 0,8-1,5 \mathrm{~mm}$; aquênio 0,7-1 × 0,4-0,7 ×0,3-0,4 mm

2. Ápice da bainha agudo ou acuminado; glumas pardas a pardo-ferrugíneas nas margens; estilete bífido; aquênio lenticular ..... E. geniculata

2. Ápice da bainha arredondado; glumas vináceas nas faces com faixa hialina marginal no ápice; estilete trífido; aquênio trígono E. minima

2.1. Eleocharis geniculata (L.) Roem. \& Schult., Syst. Veg. 2: 150 (1817).

Figura $2 \mathrm{~s}-\mathrm{v}$

Erva cespitosa $3-33 \mathrm{~cm}$. Escapo 2,5-33 $\mathrm{cm} \times$ 0,3-1 mm, seção transversal circular, septos transversais ausentes, glabro. Bainha 0,3-4,5 cm compr., ápice agudo ou acuminado. Espigueta $2,4-5(8,5) \times 1,8-2,4 \mathrm{~mm}$. Glumas 13-45, 1,4-2 $\times$ 1,1-1,5 mm, múticas, ovadas a amplamente ovadas, às vezes elípticas ou obovadas, ápice arredondado ou obtuso, medianamente 0-2-nervadas, unicarenadas, pardas a pardo-ferrugíneas nas margens, verdes a pardas na carena. Estames 3; antera 0,4-0,5 × 0,1-0,2 mm. Estilete 0,2-0,5 mm compr.; estigmas 2, 0,6-0,9 mm compr. Aquênio 0,8-1 × 0,5-0,7 $\times$ ca. $0,3 \mathrm{~mm}$, lenticular, obovoide a largamente obovoide, ápice truncado a arredondado, atropurpúreo, superfície lisa a reticulada. Estilopódio ca. 0,2 mm compr. Cerdas periânticas 7 , ferrugíneas a pardas, retrorsamente escabras.
Material examinado: BRASIL. Rio GRANDE do NoRTE: Governador Dix-Sept Rosado, Sítio Pedrinha, margem do Rio Apodi-Mossoró, 5¹9'47"S, 37²7'42"W, 22-II-2008, fl. e fr., A.R.O. Ribeiro et al. 114 (ASE, EAC, MAC, MOSS, UB, UFP, UFRN); Luís Gomes, $10 \mathrm{~km}$ após a Vila Aparecida, em direção a Tigre de Cima, 6 $21^{\prime} 05^{\prime \prime} \mathrm{S}, 38^{\circ} 25^{\prime} 09^{\prime \prime} \mathrm{W}, 28$-VIII-2008, fl. e fr., R.C. Oliveira et al. 2233 (ASE, EAC, MAC, MOSS, UB, UFP, UFRN); Tigre de Cima, nascente do Rio Apodi-Mossoró, 6²1'44"S, 38²7'51"W, 19-IX-2007, fl. e fr., A.R.O. Ribeiro et al. 3 (ASE, EAC, MAC, MOSS, UB, UFP, UFRN); Mossoró, Alto de São Manuel, Rio Mossoró, próximo à ponte da "via nova"; 16-IX-2005, fl. e fr., R.C. Oliveira et al. 1602 (ASE, EAC, MAC, MOSS, UB, UFP, UFRN); margem de lago próximo à Feira do Bode, próximo ao Rio ApodiMossoró, 511'58"S, 37019'31"W, 29-I-2008, fl. e fr., A.R.O. Ribeiro 98 (ASE, EAC, MAC, MOSS, UB, UFP, UFRN); 28-II-2008, fl. e fr., A.R.O. Ribeiro 121 (ASE, EAC, MAC, MOSS, UB, UFP, UFRN); 24-IV-2008, fl. e fr., A.R.O. Ribeiro \& A.M.S. Araújo 141 (ASE, EAC, MAC, MOSS, UB, UFP, UFRN); 21-V-2008, fl. e fr., A.R.O. Ribeiro 163 (ASE, EAC, MAC, MOSS, UB, UFP, UFRN); margem do Rio Apodi-Mossoró, atrás do Cartódromo, 511'56"S, $37^{\circ} 19^{\prime} 42^{\prime \prime} \mathrm{W}, 21-\mathrm{IX}-2007$, fl. e fr., A.R.O. Ribeiro 6 (ASE, EAC, MAC, MOSS, UB, UFP, UFRN); 19-X-2007, fl. e fr., A.R.O. Ribeiro 15 (ASE, EAC, MAC, MOSS, UB, UFP, UFRN); 23-XI-2007, fl. e fr., A.R.O. Ribeiro 84 (ASE, EAC, MAC, MOSS, UB, UFP, UFRN); 31-XII-2007, fl. e fr., A.R.O. Ribeiro 89 (ASE, EAC, MAC, MOSS, UB, UFP, UFRN); 29-I-2008, fl. e fr., A.R.O. Ribeiro 106 (ASE, EAC, MAC, MOSS, UB, UFP, UFRN); 28-II-2008, fl. e fr., A.R.O. Ribeiro 124 (ASE, EAC, MAC, MOSS, UB, UFP, UFRN); 28-III-2008, fl. e fr., A.R.O. Ribeiro 134 (ASE, EAC, MAC, MOSS, UB, UFP, UFRN); Ponte de Pedra, Rio Apodi-Mossoró, $5^{\circ} 11^{\prime} 15^{\prime \prime} \mathrm{S}, 37^{\circ} 20^{\prime} 39^{\prime \prime} \mathrm{W}$, 26-X-2007, fl. e fr., A.R.O. Ribeiro et al. 21 (ASE, EAC, MAC, MOSS, UB, UFP, UFRN).

Amplamente distribuída ao longo do rio ApodiMossoró, seja na margem do leito ou nos diques marginais, desde a nascente até a foz. Toleram ambientes salinos e áreas perturbadas. Floração e frutificação na estação seca e chuvosa, janeiro-maio e agosto-dezembro.

Espécie reconhecida pelo escapo 0,3-1 mm larg., seção transversal circular; ápice da bainha agudo ou acuminado; aquênio 0,8-1 × 0,5-0,7 × 0,3-0,3 mm, lenticular, atropurpúreo, superfície lisa a reticulada. Apresenta grande plasticidade morfológica, 
principalmente quanto à altura das touceiras, comprimento das espiguetas e forma das glumas.

Em A.R.O. Ribeiro 15, A.R.O. Ribeiro 84, A.R.O. Ribeiro 89 e A.R.O. Ribeiro 106 foi observado excepcional desenvolvimento da ráquila; foram encontradas espiguetas lanceoladas atingindo mais de $7 \mathrm{~mm}$ de compr.

2.2. Eleocharis minima Kunth, Enum. P1. 2: 139 (1837).

Figura 3 a-c

Erva cespitosa 8-15 cm. Escapo 3,5-14,5 cm $\times$ 0,2-0,4 mm, seção transversal quadrangular, às vezes circular, septos transversais ausentes, glabro. Bainha 0,6-3 cm compr., ápice arredondado. Espigueta 3,4-6 × 1,9-3,1 mm. Glumas 10-21, 1,8-2,3 × 0,8-1 mm, múticas, ovadas, ápice obtuso, arredondado ou variando de retuso a cordado, medianamente 4-8-nervadas, unicarenadas, vináceas com faixa hialina marginal nas faces, verdes na carena. Estames 3; antera 0,5-0,6 × 0,1-0,2 mm. Estilete 0,3-0,5 mm compr.; estigmas 3, 0,9-1,2 mm compr. Aquênio 0,7-0,8 × 0,4-0,5 × 0,3-0,4 mm, trígono, obovoide, ápice truncado, oliváceo a acinzentado, superfície reticulada. Estilopódio ca. 0,2 mm compr. Cerdas periânticas 6, alvas, glabras.

Material examinado: BRASIL. RIo GRANDE Do NoRTE: Francisco Dantas, $7 \mathrm{~km}$ após a vila em direção a Pau dos Ferros, 605'53"S, 38 05'28"W, 28-VIII-2008, fl. e fr., R.C. Oliveira et al. 2253 (ASE, EAC, MAC, MOSS, UB, UFP, UFRN).

Encontrada até o momento somente no município de Francisco Dantas, em lago adjacente ao rio Apodi-Mossoró, ocorrendo como aquática submersa, emergente ou em áreas não inundadas da margem. Floração e frutificação na estação seca, agosto.

Espécie reconhecida pelo escapo 0,2-0,4 $\mathrm{mm}$ larg., seção transversal quadrangular; ápice da bainha arredondado, aquênio 0,7-0,8 × 0,4-0,5 × 0,3-0,4 mm, trígono, oliváceo, superfície reticulada. Os ângulos do escapo às vezes são inconspícuos assim como encontrado por Gil \& Bove (2007) e a seção transversal é aparentemente circular.

2.3. Eleocharis mutata (L.) Roem. \& Schult., Syst. Veg. 2: 155 (1817).

Figura 3 d-e

Erva cespitosa $32-102 \mathrm{~cm}$. Escapo $29-99 \mathrm{~cm} \times$ 3,3-7 mm, seção transversal triangular, septos transversais ausentes, glabro. Bainha $8-41 \mathrm{~cm}$ compr., ápice acuminado, agudo, obtuso ou arredondado.
Espigueta 20-43 × 4-6 mm. Glumas 53-130, 3,2-3,8 $\times$ 2,3-2,7 mm, múticas, espatuliformes a oblongas, ápice obtuso, medianamente enérveas, unicarenadas, hialinas nas margens, pardas a estramíneas no centro. Estames 3; antera 1,6-2 × 0,1-0,2 mm. Estilete 1-1,3 mm compr.; estigmas 3(4), 2,6-3,5 mm compr. Aquênio 1,7-1,8 × 1,4-1,5 × 0,8-0,9 mm, lenticular, largamente obovoide, ápice truncado formando colo não constricto, ocráceo a ferrugíneo, superfície reticulada. Estilopódio 0,2-0,5 $\mathrm{mm}$ compr. Cerdas periânticas 7, ferrugíneas, retrorsamente escabras.

Material examinado: BRASIL. Rio GRANDE do NoRTE: Mossoró, lago próximo à Feira do Bode, próximo ao Rio Apodi-Mossoró, 5¹1'58"S, 37²19'31"W, 21-IX-2007, fl. e fr., A.R.O. Ribeiro 5 (ASE, EAC, MAC, MOSS, UB, UFP, UFRN); 19-X-2007, fl. e fr., A.R.O. Ribeiro 13 (ASE, EAC, MAC, MOSS, UB, UFP, UFRN); 23-XI-2007, fl. e fr., A.R.O. Ribeiro 83 (ASE, EAC, MAC, MOSS, UB, UFP, UFRN); 31-XII-2007, fl. e fr., A.R.O. Ribeiro 88 (ASE, EAC, MAC, MOSS, UB, UFP, UFRN); 29-I-2008, fl. e fr., A.R.O. Ribeiro 100 (ASE, EAC, MAC, MOSS, UB, UFP, UFRN); 28-II-2008, fl. e fr., A.R.O. Ribeiro 120 (ASE, EAC, MAC, MOSS, UB, UFP, UFRN); 24-IV-2008, fl. e fr., A.R.O. Ribeiro \& A.M.S. Araújo 138 (ASE, EAC, MAC, MOSS, UB, UFP, UFRN); 21-V-2008, fl. e fr., A.R.O. Ribeiro 159 (ASE, EAC, MAC, MOSS, UB, UFP, UFRN); margem do Rio Apodi-Mossoró, atrás do Cartódromo, 5¹1'56"S, $37^{\circ} 19^{\prime} 42^{\prime \prime} \mathrm{W}, 29-\mathrm{I}-2008$, fl. e fr., A.R.O. Ribeiro 108 (ASE, EAC, MAC, MOSS, UB, UFP, UFRN); 28-III-2008, fl. e fr., A.R.O. Ribeiro 132 (ASE, EAC, MAC, MOSS, UB, UFP, UFRN).

Espécie observada até o momento somente no município de Mossoró, formando populações abundantes nos lagos dos diques marginais, como emergente ou em áreas não inundadas na margem dos lagos. Suas touceiras podem ocupar todo o espelho d'água. Parece ser tolerante a ambientes salinos. Floração e frutificação na estação seca e chuvosa, janeiro-maio e setembro-dezembro.

A espécie pode ser confundida com Eleocharis acutangula (Roxb.) Schult. Apesar de não ter sido encontrada no rio Apodi-Mossoró, E. acutangula tem ocorrência registrada para o Estado do Rio Grande do Norte. Portanto, são pertinentes os comentários sobre a diferenciação entre estas duas espécies. Em $E$. acutangula a gluma é ovoide e o aquênio possui ápice com colo constricto, já E. mutata possui gluma espatuliforme a oblonga e aquênio com colo não constricto. 
Em A.R.O. Ribeiro 132 foram encontrados gineceus com 3 e 4 estigmas na mesma espigueta.

3. Fimbristylis Vahl, Enum. P1. 2: 285 (1805), nom. cons.

Lâmina foliar presente. Contralígula ausente. Brácteas de $1^{\text {a }}$ ordem presentes. Inflorescência terminal, composta, antela. Espiguetas 3-várias por inflorescência, normalmente desenvolvidas, aparentes. Glumas presentes, 5-várias, espiraladamente arranjadas. Flores bissexuadas, aperiantadas. Estilete decíduo; estigmas 2, fimbriados. Aquênio lenticular, superfície irregular ou reticulada com rugas longitudinais. Estilopódio ausente. Cerdas periânticas ausentes. Hipogínio ausente.

Chave para identificação das espécies de Fimbristylis do rio Apodi-Mossoró

1. Gluma ocrácea a ferrugínea nas faces, com faixa hialina marginal no ápice; aquênio castanho, superfície irregular, às vezes com verrugas F. cymosa

1. Gluma parda, às vezes com manchas vináceas nas margens; aquênio alvo a bege, superfície reticulada com rugas longitudinais ... F. dichotoma
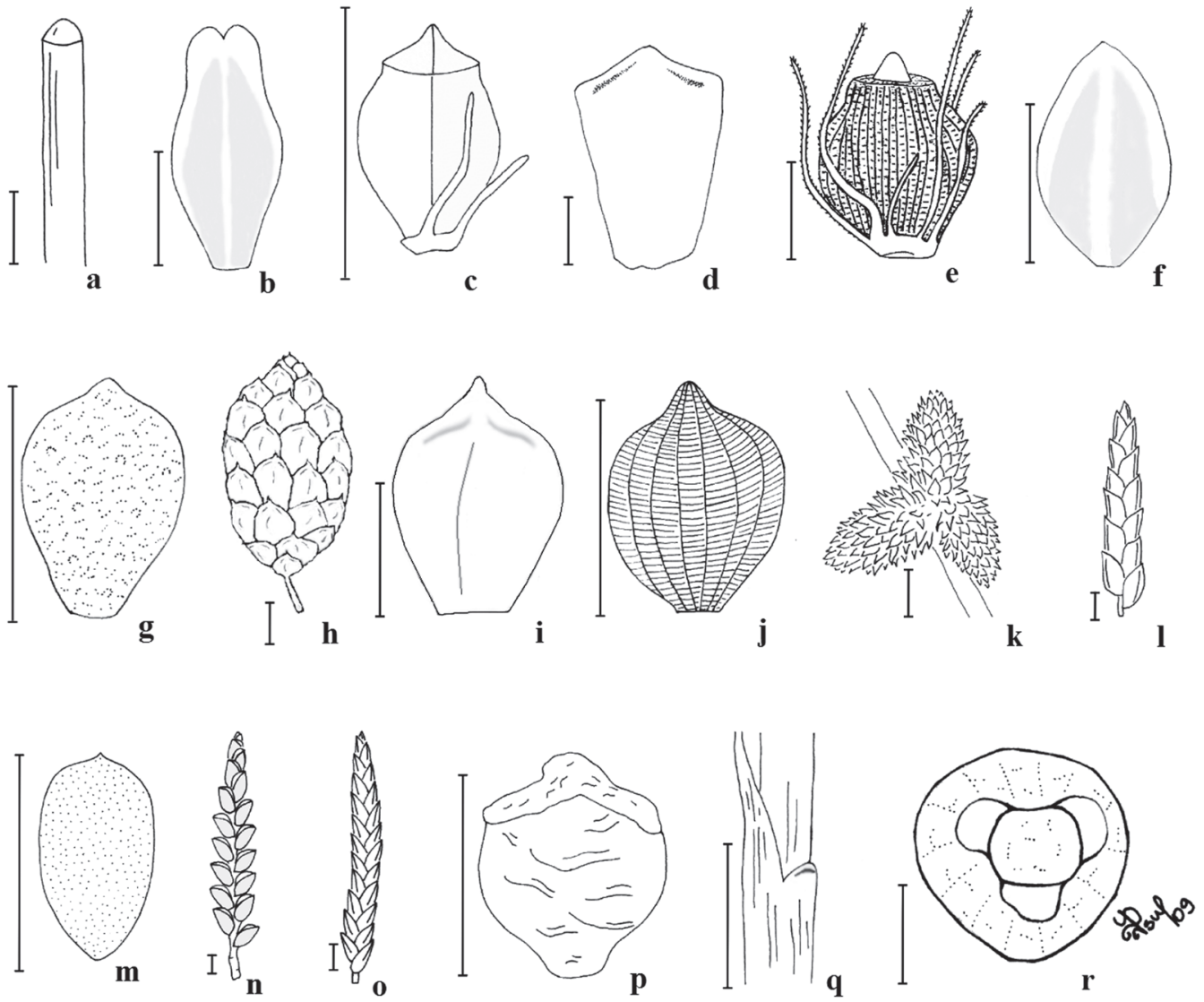

Figura 3. a-c. Eleocharis minima. a. Ápice da bainha. b. Gluma. c. Aquênio. d-e. Eleocharis mutata. d. Gluma. e. Aquênio. f-g. Fimbristylis cymosa. f. Gluma. g. Aquênio. h-j. F. dichotoma. h. Espigueta. i. Gluma. j. Aquênio. k. Lipocarpha micrantha, espigas. 1-m. Pycreus fugax. 1. Espigueta. m. Aquênio. n. Pycreus macrostachyos, espigueta. o. Pycreus polystachyos, espigueta. p. Rhynchospora contracta. q-r. Scleria reticularis. q. Lâmina foliar à esquerda, contralígula à direita, bainha abaixo. r. Hipogínio visto da base do aquênio. Escalas: a-p. 1 mm. q. 1 cm. r. 1 mm. (a-c. R.C. Oliveira et al. 2253. d-e. A.R.O. Ribeiro 13. f-g. A.R.O. Ribeiro 166. h-j. A.R.O. Ribeiro et al. 154. k. A.R.O. Ribeiro 169. 1-m. A.R.O. Ribeiro 167. n. A.R.O. Ribeiro et al. 171. o. A.R.O. Ribeiro et al. 112. p. A.R.O. Ribeiro et al.179. q-r. A.R.O. Ribeiro et al. 180).

Figure 3. a-c. Eleocharis minima. a. Sheath apex. b. Glume. c. Achene. d-e. Eleocharis mutata. d. Glume. e. Achene. f-g. Fimbristylis cymosa. f. Glume. g. Achene. h-j. F. dichotoma. h. Spikelet. i. Glume. j. Achene. k. Lipocarpha micrantha, spikes. 1-m. Pycreus fugax. 1. Spikelet. m. Achene. n. Pycreus macrostachyos, spikelet. o. Pycreus polystachyos, spikelet. p. Rhynchospora contracta. q-r. Scleria reticularis. q. Leaf blade left, contraligule right, sheath below. r. Hypogynium viewed from the base of the achene. Bars: a-p. $1 \mathrm{~mm}$. q. 1 cm. r. 1 mm. (a-c. R.C. Oliveira et al. 2253. d-e. A.R.O. Ribeiro 13. f-g. A.R.O. Ribeiro 166. h-j. A.R.O. Ribeiro et al. 154. k. A.R.O. Ribeiro 169. 1-m. A.R.O. Ribeiro 167. n. A.R.O. Ribeiro et al. 171. o. A.R.O. Ribeiro et al. 112. p. A.R.O. Ribeiro et al.179. q-r. A.R.O. Ribeiro et al. 180). 
3.1. Fimbristylis cymosa (Lam.) R.Br., Prodr. Fl. Nov. Holl.: 228 (1810).

Figura $3 \mathrm{f}-\mathrm{h}$

Erva cespitosa 21-65 cm. Escapo 10-63 cm $\times$ 0,8-2,9 mm, cilíndrico, raramente triangular com arestas arredondadas, glabro. Lâmina foliar presente, 2,5-22 $\mathrm{cm} \times 1,1-3 \mathrm{~mm}$, ápice agudo, obtuso ou arredondado, antrorsamente escabra nas margens nas porções basal, mediana e apical, às vezes antrorsamente escabra também na nervura central na porção apical. Inflorescência 1,5-6,5 × 1,5-8 cm; antela composta. Espigueta 3-8,5 (16) $\times 1,5-3 \mathrm{~mm}$. Gluma 1,2-1,6 × 1-1,2 mm, mútica, ocrácea a ferrugínea nas faces, com faixa hialina marginal no ápice, verde a ocrácea na carena. Estames 2; antera $0,5-0,6 \times 0,1-0,2 \mathrm{~mm}$. Estilete 0,4-0,7 mm compr.; estigmas 2 . Aquênio $0,7-0,8 \times$ ca. $0,6 \times$ ca. $0,4 \mathrm{~mm}$, às vezes com múcron até $0,1 \mathrm{~mm}$ compr., lenticular, castanho, superfície irregular, às vezes com verrugas.

Material examinado: BRASIL. RIo GRANDE do NoRTE: Governador Dix-Sept Rosado, Sítio Pedrinha, margem do Rio Apodi-Mossoró, 5¹9'47"S, 37²7'42"W, 22-II-2008, fl. e fr., A.R.O. Ribeiro 113 (ASE, EAC, MAC, MOSS, UB, UFP, UFRN); Mossoró, margem do Rio Apodi-Mossoró, atrás do Cartódromo, 511'56"S, 37019'42"W, 21-IX-2007, fl. e fr., A.R.O. Ribeiro 7 (ASE, EAC, MAC, MOSS, UB, UFP, UFRN); 19-X-2007, fl. e fr., A.R.O. Ribeiro 16 (ASE, EAC, MAC, MOSS, UB, UFP, UFRN); 23-XI-2007, fl. e fr., A.R.O. Ribeiro 85 (ASE, EAC, MAC, MOSS, UB, UFP, UFRN); 31-XII-2007, fl. e fr., A.R.O. Ribeiro 90 (ASE, EAC, MAC, MOSS, UB, UFP, UFRN); 29-I-2008, fl. e fr., A.R.O. Ribeiro 109 (ASE, EAC, MAC, MOSS, UB, UFP, UFRN); 28-II-2008, fl. e fr., A.R.O. Ribeiro 123 (ASE, EAC, MAC, MOSS, UB, UFP, UFRN); 28-III-2008, fl. e fr., A.R.O. Ribeiro 133 (ASE, EAC, MAC, MOSS, UB, UFP, UFRN); 21-V-2008, fl. e fr., A.R.O. Ribeiro 166 (ASE, EAC, MAC, MOSS, UB, UFP, UFRN); Ponte de Pedra, Rio Apodi-Mossoró, 511'15"S, 37²0'39"W, 26-X-2007, fl. e fr., A.R.O. Ribeiro et al. 20 (ASE, EAC, MAC, MOSS, UB, UFP, UFRN); próximo à Ponte de Ferro, Rio Mossoró, 5¹1'15"S, 37²0'39"W, 11-I-2008, fl. e fr., A.R.O. Ribeiro \& A.S. Silva 97 (ASE, EAC, MAC, MOSS, UB, UFP, UFRN).

Observada na margem do rio Apodi-Mossoró ou nos diques marginais dos municípios de Governador Dix-Sept Rosado e Mossoró. Parece ser tolerante à salinidade. Floração e frutificação na estação seca e chuvosa: janeiro-maio e setembro-dezembro.
Espécie reconhecida pela gluma 1,2-1,6 $\times$ 1-1,2 mm, ocrácea a ferrugínea nas faces, com faixa hialina marginal no ápice; estames 2 ; aquênio $0,7-0,8 \times$ ca. $0,6 \times$ ca. $0,4 \mathrm{~mm}$, às vezes com múcron até $0,1 \mathrm{~mm}$ compr., castanho, superfície irregular, às vezes com verrugas.

Excepcionalmente em A.R.O. Ribeiro 109 a seção transversal do escapo é obtusamente trígona. Em A.R.O. Ribeiro 133 a inflorescência é laxa, sendo as cimeiras facilmente distinguíveis. Em A.R.O. Ribeiro 166 a inflorescência é congesta, assemelhando-se a um glomérulo hemisférico. Entretanto, a análise minuciosa revela ser uma cimeira composta. Em A.R.O. Ribeiro 16 há extraordinário desenvolvimento da ráquila, sendo observadas espiguetas que atingem até $16 \mathrm{~mm}$ compr.

3.2. Fimbristylis dichotoma (L.) Vahl, Enum. Pl. 2: 287 (1805).

Figura 3 i-k

Erva cespitosa ca. $43 \mathrm{~cm}$. Escapo 16-40 cm $\times$ 0,5-0,7 $\mathrm{mm}$, seção transversal triangular, antrorsamente escabro e pubescente. Lâmina foliar presente, 8,5-32 cm × 0,9-1,4 mm, ápice acuminado, antrorsamente escabra ou pubescente nas margens, pubescente no hipófilo nas porções basal e mediana, antrorsamente escabra nas margens na porção apical. Inflorescência 1,3-3,4 × 0,9-3,2 cm; antela simples ou composta. Espigueta 4,8-6,5 × 2,4-3,9 mm. Gluma 2-2,5 × 2,3-2,8 mm, mútica ou mucronada, parda, às vezes com manchas vináceas nas margens, verde a parda na carena; múcron até $0,8 \mathrm{~mm}$ compr. Estames 1; antera 0,7-0,9 × 0,1-0,2 mm. Estilete 1,3-1,7 mm compr.; estigmas 2. Aquênio $0,9-1,1 \times 0,7-0,8 \times 0,5-0,6 \mathrm{~mm}$, com múcron ca. $0,1 \mathrm{~mm}$ compr., lenticular, alvo a bege, superfície reticulada com rugas longitudinais.

Material examinado: BRASIL. Rio GRANDE do NoRTE: Felipe Guerra, Cachoeira do Roncador, próximo ao Rio Apodi-Mossoró, 5³4'35"S, 37040'33"W, 26-IV-2008, fl. e fr., A.R.O. Ribeiro et al. 154 (ASE, EAC, MAC, MOSS, UB, UFP, UFRN).

Encontrada até o momento somente na Cachoeira do Roncador em Felipe Guerra, nos leitos pedregosos que deságuam no rio Apodi-Mossoró. Floração e frutificação na estação chuvosa: abril.

Espécie reconhecida pela gluma 2-2,5 $\times$ 2,3-2,8 mm, parda, às vezes com manchas vináceas nas faces; estame 1 ; aquênio $0,9-1,1 \times 0,7-0,8 \times$ 
0,5-0,6 mm, com múcron ca. 0,1 mm compr., alvo a bege, superfície reticulada com rugas longitudinais.

4. Lipocarpha R.Br. in J.H.Tuckey, Narr. Exped. Zaire: 459 (1818).

Lâmina foliar presente. Contralígula ausente ou presente. Brácteas de $1^{\mathrm{a}}$ ordem presentes. Inflorescência terminal ou pseudolateral, simples ou composta, glomérulo ou espiga. Espiguetas 5-várias por inflorescência, reduzidas, ocultas pela bráctea da espigueta. Glumas ausentes. Flores bissexuadas, aperiantadas. Estilete decíduo; estigmas 2, glabro. Aquênio cilíndrico, superfície reticulada a papilosa. Estilopódio ausente. Cerdas periânticas ausentes. Hipogínio ausente.

4.1. Lipocarpha micrantha (Vahl) G.C.Tucker, J. Arnold Arbor:: 68: 410 (1987).

Figura 3 1-m

Erva cespitosa 9-25 cm. Lâmina foliar 0,5-7 cm $\times$ 0,7-1,1 mm. Bainha 0,5-2,2 cm compr. Brácteas de $1^{\mathrm{a}}$ ordem 1-2, a mais longa ereta parecendo ser a continuação do escapo. Inflorescência pseudolateral, composta. Bráctea da espigueta 0,6-0,8 $\times 0,3-0,4 \mathrm{~mm}$, mucronada, obovada a oblanceolada, ápice agudo, obtuso ou arredondado, decídua, parda a vinácea nas margens, verde, parda ou vinácea na carena; múcron 0,1-0,2 mm compr. Gluma ausente. Estames 1; antera ca. $0,2 \times 0,1-0,2 \mathrm{~mm}$. Estilete ca. 0,2 mm compr.; estigmas 2 . Aquênio $0,4-0,6 \times$ ca. $0,2 \mathrm{~mm}$, com múcron ca. $0,1 \mathrm{~mm}$ compr., bege a ocráceo.

Material examinado: BRASIL. RIo GRANDE Do NoRTE: Felipe Guerra, Cachoeira do Roncador, próximo ao Rio Apodi-Mossoró, 5³4'35"S, 37²40'33"W, 26-IV-2008, fl. e fr., A.R.O. Ribeiro et al. 153 (ASE, EAC, MAC, MOSS, UB, UFP, UFRN); Luís Gomes, estrada para Cachoeira do Rela, margem de afluente do Rio Apodi-Mossoró, 6 ${ }^{\circ} 23^{\prime} 51^{\prime \prime} \mathrm{S}, 38^{\circ} 22^{\prime} 52^{\prime \prime} \mathrm{W}$, 31-V-2008, fl. e fr., A.R.O. Ribeiro et al. 212 (ASE, EAC, MAC, MOSS, UB, UFP, UFRN); Tigre de Cima, nascente do Rio Apodi-Mossoró, 6²1'26"S, $38^{\circ} 27^{\prime} 42^{\prime \prime} \mathrm{W}, 30-\mathrm{V}-2008$, fl. e fr., A.R.O. Ribeiro et al. 184 (ASE, EAC, MAC, MOSS, UB, UFP, UFRN); fl. e fr., A.R.O. Ribeiro et al. 201 (ASE, EAC, MAC, MOSS, UB, UFP, UFRN); Mossoró, margem do Rio Apodi-Mossoró, próximo ao Cartódromo, $5^{\circ} 11^{\prime} 56^{\prime \prime S}$, 37'19'42"W, 24-IV-2008, fl. e fr., A.R.O. Ribeiro \& A.M.S. Araújo 146 (ASE, EAC, MAC, MOSS, UB, UFP, UFRN); 21-V-2008, fl. e fr., A.R.O. Ribeiro 169 (ASE, EAC, MAC, MOSS, UB, UFP, UFRN).
Amplamente distribuída, desde a nascente do rio Apodi-Mossoró até o município de Mossoró, ocorrendo em leitos pedregosos, margem do rio ou circundando os lagos formados pelos diques marginais. Floração e frutificação na estação chuvosa, abril e maio.

Espécie reconhecida pela inflorescência pseudolateral; bráctea de $1^{\mathrm{a}}$ ordem mais longa em disposição ereta, parecendo ser a continuação do escapo; bráctea da espigueta $0,6-0,8 \times 0,3-0,4 \mathrm{~mm}$; gluma ausente; aquênio $0,4-0,6 \times$ ca. $0,2 \mathrm{~mm}$, com múcron ca. $0,1 \mathrm{~mm}$ compr., obovoide ou oblanceolado, bege a ocráceo.

\section{Pycreus P.Beauv., Fl. Oware 2: 48 (1816).}

Lâmina foliar presente. Contralígula ausente. Brácteas de $1^{\mathrm{a}}$ ordem presentes. Inflorescência terminal, simples ou composta, antela, glomérulo, espiga ou grupo digitado. Espiguetas 3-várias por inflorescência, normalmente desenvolvidas, aparentes. Glumas presentes, 8-várias, disticamente arranjadas. Flores bissexuadas, aperiantadas. Estilete decíduo; estigmas 2, glabros. Aquênio lenticular, superfície papilosa ou reticulada com uma papila em cada célula. Estilopódio ausente. Cerdas periânticas ausentes. Hipogínio ausente.

Chave para identificação das espécies de Pycreus do rio Apodi-Mossoró

1. Gluma 1,6-2 mm larg., ferrugínea a castanhovinácea nas faces com faixa hialina marginal no ápice; aquênio atropurpúreo 1,2-1,4 × 0,7-1 mm ......

P. macrostachyos

1. Gluma 0,8-1,4 mm larg., parda, amarelada, ocrácea ou ferrugínea nas margens; aquênio pardo, ocráceo, ferrugíneo ou castanho $0,8-1 \times 0,3-0,5 \mathrm{~mm}$

2.Espigueta 1,6-2,1 mm larg.; androceu 2estames, antera ca. 0,2 mm compr. ........ P. fugax

2. Espigueta 1,1-1,3 mm larg.; androceu 1estames, antera $0,4-0,5 \mathrm{~mm}$ compr.... P. polystachyos

5.1. Pycreus fugax (Liebm.) C.D.Adams, Ann. Missouri Bot. Gard. 78: 254 (1991).

Figura 3 n-p

Erva cespitosa 12-33 cm. Escapo 4,5-30 $\mathrm{cm} \times$ 0,5-1,2 mm, seção transversal triangular. Lâmina foliar presente, $1,4-15 \mathrm{~cm} \times 1,3-2,1 \mathrm{~mm}$. Inflorescência 3-13 $\times$ 2,5-12 cm; antela de glomérulos ou grupos digitados. Espigueta 6-23 × 1,6-2,1 $\times$ ca. $0,2 \mathrm{~mm}$. Ráquila com entrenós $0,5-0,7 \mathrm{~mm}$ compr. Glumas 
8-31, 1,4-1,8 × 1,1-1,4 mm, múticas ou mucronadas, pardas, ocráceas ou ferrugíneas nas margens, verdes na carena; múcron até $0,1 \mathrm{~mm}$ compr. Estames 2; antera ca. $0,2 \times 0,1-0,2 \mathrm{~mm}$. Estilete $0,2-0,3 \mathrm{~mm}$ compr. Aquênio 0,9-1 × 0,4-0,5 × ca. 0,2 mm, com múcron ca. $0,1 \mathrm{~mm}$ compr., oblongo ou obovoide, ápice arredondado ou obtuso, pardo a castanho.

Material examinado: BRASIL. Rio GRAnde Do NorTE: Luís Gomes, estrada para Cachoeira do Rela, margem de afluente do Rio Apodi-Mossoró, 6 23'51"S, $38^{\circ} 22^{\prime} 52^{\prime \prime} \mathrm{W}, 31-\mathrm{V}-2008$, fl. e fr., A.R.O. Ribeiro et al. 209 (ASE, EAC, MAC, MOSS, UB, UFP, UFRN); estrada para Tigre de Cima, margem de afluente do Rio Apodi-Mossoró, próximo à ponte da Baixa do Almeida, 6²3'53"S, 38 24'36"'W, 30-V-2008, fl. e fr., A.R.O. Ribeiro et al. 174 (ASE, EAC, MAC, MOSS, UB, UFP, UFRN); Tigre de Cima, nascente do Rio Apodi-Mossoró, 6² 21'26"S, 38²7'42"W, 30-V-2008, fl. e fr., A.R.O. Ribeiro et al. 200 (ASE, EAC, MAC, MOSS, UB, UFP, UFRN); Mossoró, margem do Rio Apodi-Mossoró, próximo ao Cartódromo, $5^{\circ} 11^{\prime} 56^{\prime \prime S}$, 37'19'42"W, 24-IV-2008, fl. e fr., A.R.O. Ribeiro \& A.M.S. Araújo 145 (ASE, EAC, MAC, MOSS, UB, UFP, UFRN); 21-V-2008, fl. e fr., A.R.O. Ribeiro 167 (ASE, EAC, MAC, MOSS, UB, UFP, UFRN).

Foi coletada em Luís Gomes na margem de riachos periódicos, situados na nascente do rio ApodiMossoró e no município de Mossoró, ocorrendo na margem do rio ou nos diques marginais. Floração e frutificação na estação chuvosa: abril e maio.

A espécie pode ser confundida com $P$. polystachyos. Em P. fugax a espigueta mede 1,6-2,1 mm larg.; gluma 1,4-1,8 mm compr.; androceu 2-estaminado, antera ca. 0,2 mm compr. Em P. polystachyos a espigueta mede 1,1-1,3 mm larg.; gluma 1,1-1,4 compr.; androceu 1-estaminado, antera $0,4-0,5 \mathrm{~mm}$ compr.

5.2. Pycreus macrostachyos (Lam.) J.Raynal, Kew Bull. 23: 314 (1969).

Figura $3 \mathrm{q}$

Erva cespitosa (15-)43-97 cm. Escapo 12-75 cm $\times$ (0,3-)1,3-5 mm, seção transversal triangular, glabro. Lâmina foliar presente, $3,5-32 \mathrm{~cm} \times 1,1-8,5 \mathrm{~mm}$, Inflorescência (1)4,5-22 × (1,3-)3,5-18 cm; antela de espigas ou grupos digitados. Espigueta 7-32 ×2,7-3,1 $\times$ 0,3-0,4 mm. Ráquila com entrenós $0,5-0,8 \mathrm{~mm}$ compr. Glumas 9-55, 1,5-1,9 × 1,6-2 mm, múticas ou mucronadas, ferrugíneas a castanho-vináceas nas faces com faixa hialina marginal no ápice, verdes na carena; múcron até $0,1 \mathrm{~mm}$ compr. Estames 3; antera
0,4-0,6 $\times$ 0,1-0,2 mm. Estilete 0,2-0,3 mm compr. Aquênio 1,2-1,4 × 0,7-1 × 0,2-0,3 mm, com múcron ca. $0,1 \mathrm{~mm}$ compr., obovoide, ápice arredondado, atropurpúreo.

Material examinado: BRASIL. Rio GRAnde Do Norte: Luís Gomes, estrada para Tigre de Cima, margem de afluente do Rio Apodi-Mossoró, próximo à ponte da Baixa do Almeida, $6^{\circ} 23^{\prime} 53^{\prime \prime} \mathrm{S}, 38^{\circ} 24^{\prime} 36^{\prime \prime} \mathrm{W}$, 30-V-2008, fl. e fr., A.R.O. Ribeiro et al. 171 (ASE, EAC, MAC, MOSS, UB, UFP, UFRN); Tigre de Cima, nascente do Rio Apodi-Mossoró, 6 21'44"S, $38^{\circ} 27^{\prime} 51^{\prime \prime} \mathrm{W}, 24-\mathrm{VIII}-2007$, fl. e fr., A.R.O. Ribeiro et al. 1 (ASE, EAC, MAC, MOSS, UB, UFP, UFRN); Mossoró, margem do Rio Apodi-Mossoró, próximo ao Cartódromo, $5^{\circ} 11^{\prime} 56^{\prime \prime} \mathrm{S}, 37^{\circ} 19^{\prime} 42^{\prime \prime} \mathrm{W}, 24-\mathrm{IV}-2008$, fl. e fr., A.R.O. Ribeiro \& A.M.S. Araújo 144 (ASE, EAC, MAC, MOSS, UB, UFP, UFRN); 21-V-2008, fl. e fr., A.R.O. Ribeiro 165 (ASE, EAC, MAC, MOSS, UB, UFP, UFRN).

Encontrada em Luís Gomes populações na margem de riachos periódicos que compõem a nascente do rio Apodi-Mossoró e em Mossoró ocorre na margem do rio ou nos diques marginais. Floração e frutificação na estação seca e chuvosa, abril, maio e agosto. Durante o mês de agosto esta espécie teve florescimento registrado somente para o município de Luís Gomes, na nascente do rio Apodi-Mossoró.

Espécie reconhecida pela gluma 1,5-1,9 $\times$ 1,6-2 mm, ferrugínea a castanho-vinácea nas faces com faixa hialina marginal no ápice; aquênio 1,2-1,4 × 0,7-1 × 0,2-0,3 mm, com múcron ca. $0,1 \mathrm{~mm}$ compr., obovoide, atropurpúreo.

Em A.R.O. Ribeiro \& A.M.S. Araújo 144 o porte é reduzido. A touceira atinge apenas $15 \mathrm{~cm}$ de altura; o escapo pode medir ca. $0,3 \mathrm{~mm}$ larg.; a inflorescência pode ter uma única ordem em alguns perfilhos, variando de espiga a grupo digitado solitário no ápice do escapo; as medidas da inflorescência podem alcançar ca. $1 \times$ ca. $1,3 \mathrm{~cm}$ em alguns perfilhos.

5.3. Pycreus polystachyos (Rottb.) P.Beauv., Fl. Oware 2: 48 (1816).

Figura $3 \mathrm{r}$

Erva cespitosa 8,5-57 cm. Escapo 6,3-53 cm $\times$ 0,9-2,6 mm, seção transversal triangular. Lâmina foliar presente, $1-22,5 \mathrm{~cm} \times 1,2-5 \mathrm{~mm}$. Inflorescência 1,6-2,6 $\times$ 2,3-5,5 cm;2-3 ordens; glomérulo hemisférico ou antela de espigas. Espigueta 5-12 $\times$ $1,1-1,3 \times$ ca. $0,2 \mathrm{~mm}$. Ráquila com entrenós $0,4-0,6 \mathrm{~mm}$ compr. Glumas 10-19, 1,1-1,4 × 0,8-1,2 mm, múticas ou mucronadas, amareladas a ocráceas nas 
margens, verdes, estramíneas ou pardas na carena; múcron até $0,1 \mathrm{~mm}$ compr. Estames 1 ; antera $0,4-0,5 \times 0,1-0,2 \mathrm{~mm}$. Estilete 0,3-0,5 mm compr. Aquênio 0,8-0,9 × 0,3-0,4 × 0,15-0,20 mm, com múcron ca. $0,1 \mathrm{~mm}$ compr., estreitamente oblongo ou lanceolado, às vezes oblanceolado, ápice obtuso ou arredondado, ocráceo a ferrugíneo.

Material examinado: BRASIL. RIo GRANDE do NoRTE: Governador Dix-Sept Rosado, Sítio Pedrinha, margem do Rio Apodi-Mossoró, 5¹9'47"S, 37²7'42"W, 22-II-2008, fl. e fr., A.R.O. Ribeiro et al. 112 (ASE, EAC, MAC, MOSS, UB, UFP, UFRN); Mossoró, Ponte de Pedra, Rio Apodi-Mossoró, 5¹1'15"S, 37²0'39"W, 26-X-2007, fl. e fr., A.R.O. Ribeiro et al. 22 (ASE, EAC, MAC, MOSS, UB, UFP, UFRN).

Coletada nos municípios de Governador Dix-Sept Rosado e Mossoró na margem do rio Apodi-Mossoró ou como aquática emergente. Floração e frutificação na estação seca e chuvosa: fevereiro e outubro.

A espécie pode ser confundida com P. fugax (ver comentários sob 5.1).

6. Rhynchospora Vahl, Enum. P1. 2: 229 (1805), nom. cons.

Lâmina foliar presente. Contralígula ausente. Brácteas de $1^{a}$ ordem presentes. Inflorescência composta, terminal, racemo, corimbo, espiga ou glomérulo. Espiguetas 5-várias por inflorescência, normalmente desenvolvidas, aparentes. Glumas presentes, 2-várias, espiraladamente arranjadas. Flores bissexuadas, aperiantadas. Estilete com base persistente; estigmas 2, glabros. Aquênio lenticular, superfície transversalmente rugosa. Estilopódio presente. Cerdas periânticas ausentes. Hipogínio ausente.

6.1. Rhynchospora contracta (Nees) J.Raynal, Adansonia, n.s., 17: 277 (1978).

Figura $3 \mathrm{~s}-\mathrm{t}$

Erva cespitosa 9-36 cm. Escapo $4-13 \mathrm{~cm} \times$ 0,6-1,1 mm, seção transversal triangular, glabro. Lâmina foliar 4-18 cm × 1,2-3 mm. Inflorescência 4,5-27 $\times$ 0,5-4 cm; racemo de corimbos de fascículos. Espigueta 1,1-1,5 × 1,1-2 mm. Gluma $1-1,3 \times 0,6-1,4 \mathrm{~mm}$, mútica ou mucronada, parda, ocrácea ou ferrugínea nas margens, verde a ocrácea na carena; múcron até 1,3 mm compr. Estames 2; antera $0,2-0,3 \times 0,1-0,2 \mathrm{~mm}$. Estilete 0,2-0,4 $\mathrm{mm}$ compr.; estigmas 2. Aquênio 0,8-1 ×0,8-1 mm, obovoide ápice obtuso ou truncado, ocráceo a castanho, às vezes alvo, superfície transversalmente rugosa. Estilopódio deltoide. Cerdas periânticas ausentes.
Material examinado: BRASIL. Rio GRAnde do NorTE: Luís Gomes, estrada para Cachoeira do Rela, margem de afluente do Rio Apodi-Mossoró, 6 23 '51"S, $38^{\circ} 22^{\prime} 52^{\prime \prime} \mathrm{W}, 31-\mathrm{V}-2008$, fl. e fr., A.R.O. Ribeiro et al. 211 (ASE, EAC, MAC, MOSS, UB, UFP, UFRN); estrada para Tigre de Cima, margem de afluente do Rio Apodi-Mossoró, próximo à ponte da Baixa do Almeida, 62 $3^{\prime} 53^{\prime \prime} \mathrm{S}, 38^{\circ} 24^{\prime} 36^{\prime \prime} \mathrm{W}, 30-\mathrm{V}-2008$, fl. e fr., A.R.O. Ribeiro et al. 179 (ASE, EAC, MAC, MOSS, UB, UFP, UFRN); Tigre de Cima, nascente do Rio Apodi-Mossoró, 6²1'26"S, 38²7'42"W, 30-V-2008, fl. e fr., A.R.O. Ribeiro et al. 183 (ASE, EAC, MAC, MOSS, UB, UFP, UFRN); 6 $21^{\prime} 44^{\prime \prime S}$, $38^{\circ} 27^{\prime} 51^{\prime \prime W}, 24-\mathrm{VIII}-2007$, fl. e fr., A.R.O. Ribeiro et al. 2 (ASE, EAC, MAC, MOSS, UB, UFP, UFRN); Mossoró, margem do Rio Apodi-Mossoró, próximo ao Cartódromo, 5 $11^{\prime} 56$ "S, 37²19'42"W, 24-IV-2008, fl. e fr., A.R.O. Ribeiro \& A.M.S. Araújo 148 (ASE, EAC, MAC, MOSS, UB, UFP, UFRN).

Coletada na nascente do rio Apodi-Mossoró e no município de Mossoró, ocorrendo em leitos pedregosos, na margem do rio ou circundando os lagos formados pelos diques marginais. Floração e frutificação na estação seca e chuvosa, abril, maio e agosto. O florescimento durante o mês de agosto foi observado somente no município de Luís Gomes, na nascente do rio.

Espécie reconhecida pela inflorescência com ramos de $2^{\mathrm{a}}$ ordem do tipo corimbo, raramente racemo; espigueta $1,1-1,5 \times 1,1-2 \mathrm{~mm}$; aquênio 0,8-1 $\times 0,8-1 \mathrm{~mm}$, obovoide a largamente obovoide, ocráceo a castanho, às vezes alvo, superfície transversalmente rugosa; cerdas periânticas ausentes.

7. Scleria P.J.Bergius, Kongl. Vetensk. Acad. Handl. 26: 142 (1765).

Lâmina foliar presente. Contralígula presente. Brácteas de $1^{\mathrm{a}}$ ordem presentes. Inflorescência terminal, composta, panícula. Espiguetas 5-várias por inflorescência, normalmente desenvolvidas, aparentes. Glumas presentes, 2-várias, disticamente arranjadas. Flores unissexuadas, periantadas. Estilete decíduo; estigmas 3, fimbriados. Aquênio trígono, globoide, superfície reticulada. Estilopódio ausente. Cerdas periânticas ausentes. Hipogínio presente.

7.1. Scleria reticularis Michx., Fl. Bor.-Amer. 2: 167 (1803).

Figura $3 \mathrm{u}-\mathrm{x}$

Erva cespitosa $79 \mathrm{~cm}$. Escapo 41-52 $\mathrm{cm} \times$ 1,7-3 mm, seção transversal triangular, glabro a 
retrorsamente escabro na porção basal, retrorsamnente escabro na porção mediana, glabro na porção apical. Lâmina foliar presente, $3,5-34 \mathrm{~cm} \times 3-5,5 \mathrm{~mm}$. Contralígula 0,4-0,9 mm compr. Bainha $6,5-14 \mathrm{~cm}$ compr. Bráctea de $1^{\mathrm{a}}$ ordem 0,8-23 cm $\times 1,5-5,1 \mathrm{~mm}$. Inflorescência 23-36 × 2,5-4 cm; panícula; espiguetas masculinas e femininas mescladas na mesma inflorescência. Espigueta masculina 3,7-4,3 × 1,2-1,8 $\times$ 0,5-0,7 mm. Gluma masculina 3,3-3,4 × 1,2-1,6 mm, mútica, mucronada ou aristada, hialina, parda ou vinácea nas margens, verde a vinácea na carena; múcron/arista até $0,4 \mathrm{~mm}$ compr. Espigueta feminina $3,8-4,5 \times 2,5-5 \times 2,1-2,3 \mathrm{~mm}$. Gluma feminina 3,5-4,1 × 1,7-2,2 mm, mútica, mucronada ou aristada, parda a vinácea nas margens, verde a ocrácea na carena; múcron/arista até $1 \mathrm{~mm}$ compr. Estames 3; antera 1,2-1,6 × 0,1-0,2 mm. Estilete 0,9-1,1 mm compr.; estigmas 3, 1-1,3 mm compr. Aquênio 2,4-2,6×2,1-2,3 mm, com múcron 0,2-0,3 mm compr., ovoide, ápice arredondado ou obtuso, alvo, superfície reticulada, às vezes com verrugas. Estilopódio ausente. Hipogínio presente, alvo.

Material examinado: BRASIL. RIo GRANDE do NoRTE: Luís Gomes, estrada para Tigre de Cima, margem de afluente do Rio Apodi-Mossoró, próximo à ponte da Baixa do Almeida, 6⒉'53"S, 38²4'36"W, 30-V-2008, fl. e fr., A.R.O. Ribeiro et al. 180 (ASE, EAC, MAC, MOSS, UB, UFP, UFRN).

Encontrada até o momento somente no município de Luís Gomes, na margem de riachos que compõem a nascente do rio Apodi-Mossoró, em campos encharcados. Floração e frutificação na estação chuvosa, maio.

Espécie reconhecida pelo aquênio 2,4-2,6 $\times$ 2,1-2,3 × 2,1-2,3 mm, com múcron 0,2-0,3 mm compr., largamente ovoide a muito largamente ovoide, ápice arredondado ou obtuso, alvo, superfície reticulada, às vezes com verrugas; estilopódio ausente; hipogínio presente, alvo.

\section{Agradecimentos}

À Petrobrás Ambiental, pelo apoio financeiro; ao CNPq e ao Programa PICI-UFERSA, pela concessão de bolsa ao primeiro Autor; à Suzana Maria dos Santos Costa, pelo inestimável auxílio e discussão sobre o trabalho; ao José Erivaldo de Araújo (Vavá), Luís Belo (Seu Luís) e Maiele Leandro da Silva, pelo auxílio nos trabalhos de campo; à técnica de herbário Antonia Kátia Pinheiro de Medeiros, pelo auxilio e treinamento em herborização; aos estagiários do herbário MOSS, pelo estímulo e discussão sobre o trabalho.

\section{Literatura citada}

Ahmad, M., Mahayrookh, Mehjabeen, Rehman, A.B. \& Jahan, N. 2012. Analgesic, antimicrobial and cytotoxic effect of Cyperus rotundus ethanol extract. Pakistan Journal of Pharmacology 29: 7-13.

Alves, M. \& Martins, S. 2009. Cyperaceae. In: M. Alves, M.F. Araújo, J.R. Maciel, S. Martins. Flora de Mirandiba. Associação Plantas do Nordeste, Recife.

Alves, M., Araújo, A.C., Prata, A.P., Vitta, F., Hefler, S., Trevisan R., Gil, A.B., Martins, S. \& Thomas, W.W. 2009. The Catalogue of Diversity of Cyperaceae in Brazil. Rodriguésia 60: 771-782.

Alves, M., Araújo, A.C., Hefler, S.M., Trevisan, R., Silveira, G.H. \& Luz, C.L. 2012. Cyperaceae. In: R.C. Forzza et al. Lista de Espécies da Flora do Brasil. Jardim Botânico do Rio de Janeiro. http://floradobrasil. jbrj.gov.br/2012/FB000100 (acesso em 05.IV.2013).

Andrade-Lima, D. 1981. The Caatingas dominium. Revista Brasileira de Botânica 4: 149-153.

Araújo,A.C.\& Longhi-Wagner, H.M. 1996. Levantamento taxonômico de Cyperus L. subg. Anosporum (Nees) C.B. Clarke (Cyperaceae - Cypereae) no Rio Grande do Sul, Brasil. Acta Botanica Brasilica 10: 153-192.

Araújo, F.S., R.C. Costa, M.A. Figueiredo \& E.P. Nunes. 2005. Vegetação e flora fanerogâmica da área Reserva Serra das Almas, Ceará. In: F. S. de Araújo, M. J. N. Rodal and M. R. de V. Barbosa (org.). Análise das variações da biodiversidade do bioma caatinga: suporte a estratégias regionais de conservação. Série Biodiversidade 12. Ministério do Meio Ambiente, Brasília-DF, pp. 94-121.

Bendixen, L.E. \& Nandihalli, U.B. 1987. Worldwide Distribution of Purple and Yellow Nutsedge (Cyperus rotundus and C. esculentus). Weed Technology 1: 61-65.

Cordeiro, L.A.M., Reis, M.S., Agnes, E.L. \& Cecon, P.R. 2006. Efeito do plantio direto no controle de tiririca (Cyperus rotundus L.) e outras plantas daninhas na cultura do milho. Revista Brasileira de Herbicidas 1: $1-9$.

Denton, M.F. 1978. Taxonomic treatment of the "Luzulae" group of Cyperus. Contributions from the University of Michigan Herbarium, Ann Arbor, Michigan, v. 11, pp. 197-271.

Dor, E. \& Hershenhorn, J. 2013. Effect of Low Temperature on Purple Nutsedge (Cyperus rotundus) Reproductive Biology. Weed Science 61: 239-243.

Façanha, G.S., Castro, R.F. \& Santana, G.P. 2007. Fitoextração de pb2+ em latossolo contaminado por pb2+, cr2+ e zn2+ utilizando as espécies Cyperus surinamensis e Panicum maximum. Anais do XLVII Congresso Brasileiro de Química. http://www.abq.org. br/cbq/2007/trabalhos/13/13-735-701.htm (acesso em 06.VII.2008). 
FAO. 2013. Cyperus rotundus L. http://www.fao.org/ agriculture/crops/core-themes/theme/biodiversity/ weeds/listweeds/cyp_rot/en/ (acesso em 08.X.2013)

Freitas, R.C.A., Santos, M.L.G. \& Matias, L.Q. 2011. Checklist das monocotiledôneas do Ceará, Brasil. Revista Caatinga 24: 75-84.

Gil, A.S.B. \& Bove, C.P. Eleocharis R. Br. 2007. (Cyperaceae) no Estado do Rio de Janeiro, Brasil. Biota Neotropica 7: 163-193.

Goetghebeur, P. 1998. Cyperaceae. In: K. Kubitzki (ed.). The families and genera of vascular plant: IV. Flowering plants - monocotyledons. Berlin: Springer-Verlag, pp. 141-190.

Guarise, N.J. \& Vegetti, A.C. 2007. Inflorescences structure of Cyperus L. section Luzuloidei Kunth (Cyperaceae). Plant Systematics and Evolution 271: 41-63.

Henry-Silva, G.G., Moura, R.S.T. \& Dantas, L.L.O. 2010. Richness and distribution of aquatic macrophytes in Brazilian semi-arid aquatic ecosystems. Acta Limnologica Brasiliensia 22: 147-156.

IDEMA. 2007. Estado do Rio Grande do Norte: esboço da vegetação. http://www.portal.rn.gov.br/ contentproducao/aplicacao/idema/anuario/anteriores/ anuario2008/caracterizacao_territorio.html (acesso em 05.IV.2013).

Jahan, N., Rahman, K.U. \& Ali, S. 2012. Cardioprotective and antilipidemic potential of Cyperus rotundus in chemically induced cardiotoxicity. International Journal of Agriculture and Biology 14: 989-992

Kükenthal, G. 1956. Cyperaceae-Scirpoideae-Cypereae. In: A. Engler (ed.). Das Pflanzenreich: regni vegetabilis conspectus. 2 ed. H.R. Engelmann, Weinheim.

Luceño, M., Alves, M.V. \& Mendes, A.P.N. 1997. Catálogo florístico y claves de identificación de las ciperáceas de los Estados de Paraíba y Pernambuco (nordeste de Brasil). Anales del Jardín Botánico de Madrid 55: 67-100.
Nascimento, C.E.S., Rodal, M.J.N. \& Cavalcanti, A.C. 2003. Phytosociology of the remaining xerophytic woodland associated to an environmental gradient at the banks of the São Francisco River - Petrolina, Pernambuco, Brazil. Revista Brasileira de Botânica 26: 271-287.

Radford, A.E., Dickison, W.C., Massey, J.R. \& Bell, C.R. 1974. Vascular Plants Systematics. Harper e How, New York.

Silva, J.M.C., Tabarelli, M., Fonseca, M.T. 2004. Áreas e ações prioritárias para conservação da Caatinga. In: J.M.C. Silva, M. Tabarelli, M.T. Fonseca \& L.V. Lins (orgs.). Biodiversidade da Caatinga: áreas e ações prioritárias para a conservação. Ministério do Meio Ambiente, Universidade Federal de Pernambuco, Brasília, DF, parte 5, pp. 348-382.

Singh, N.B., Pandey, B.N. \& Singh, A. 2009. Allelopathic effects of Cyperus rotundus extract in vitro and ex vitro on banana. Acta Physiologiae Plantarum 31: 633-638.

Sivapalan, S.R. 2013. Medicinal uses and Pharmacological activities of Cyperus rotundus Linn - A Review. International Journal of Scientific and Research Publications 3: 1-8.

Souza, C.E.O. \& Conceição, G.M. 2009. Espécies de Cyperaceae de ocorrência no município de Caxias, Maranhão, Brasil. Pesquisa em Foco 17: 26-31.

Souza, J.A.N. \& M.J.N. Rodal. 2010. Levantamento florístico em trecho de vegetação ripária de Caatinga no rio Pajeú, Floresta/Pernambuco-Brasil. Caatinga 23: $54-63$.

Thiers, B. 2013. Index Herbariorum: A global directory of public herbaria and associated staff. New York Botanical Garden's Virtual Herbarium. http://sweetgum.nybg.org/ ih/ (acesso em 05.IV.2013).

Tucker, G.C. 1994. Systematic Botany Monographs: revision of the Mexican species of Cyperus (Cyperaceae). The American Society of Plant Taxonomists, Ann Arbor, Michigan, v. 43.

Walter, B.M.T. \& Cavalcanti, T.B. 2005. Fundamentos para a Coleta de Germoplasma Vegetal. Embrapa Recursos Genéticos e Biotecnologia, Brasília-DF, pp. 217-240. 